\title{
Bulk and Surface Conformations in Solid-State Lovastatin: Spectroscopic and Molecular Dynamics Studies
}

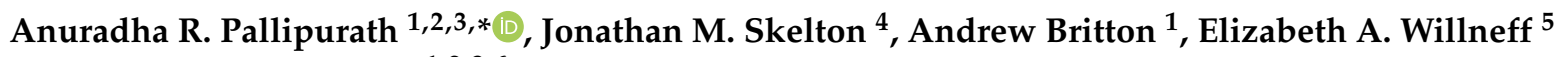 \\ and Sven L. M. Schroeder 1,2,3,6 \\ 1 School of Chemical and Process Engineering, University of Leeds, Leeds LS2 9JT, UK; \\ A.Britton@leeds.ac.uk (A.B.); S.L.M.Schroeder@leeds.ac.uk (S.L.M.S.) \\ 2 Research Complex at Harwell, Oxfordshire OX11 OFA, UK \\ 3 EPSRC Centre for Innovative Manufacturing in Continuous Manufacturing and Advanced Crystallisation, \\ University of Strathclyde, Glasgow G1 1RD, UK \\ 4 Department of Chemistry, University of Manchester, Oxford Road, Manchester M13 9PL, UK; \\ jonathan.skelton@manchester.ac.uk \\ 5 School of Design, University of Leeds, Leeds LS2 9JT, UK; E.A.Willneff@leeds.ac.uk \\ 6 Diamond Light Source Ltd., Oxfordshire OX11 0DE, UK \\ * Correspondence: a.r.pallipurath@leeds.ac.uk
}

Citation: Pallipurath, A.R.; Skelton, J.M.; Britton, A.; Willneff, E.A.; Schroeder, S.L.M. Bulk and Surface Conformations in Solid-State Lovastatin: Spectroscopic and Molecular Dynamics Studies. Crystals 2021, 11, 509. https://doi.org/ $10.3390 /$ cryst11050509

Academic Editor: Shujun Zhang

Received: 1 April 2021

Accepted: 23 April 2021

Published: 4 May 2021

Publisher's Note: MDPI stays neutral with regard to jurisdictional claims in published maps and institutional affiliations.

Copyright: (c) 2021 by the authors. Licensee MDPI, Basel, Switzerland. This article is an open access article distributed under the terms and conditions of the Creative Commons Attribution (CC BY) license (https:// creativecommons.org/licenses/by/ $4.0 /)$.
Abstract: Conformational flexibility in molecules can give rise to a range of functional group terminations at crystal surfaces and dynamic disorder in the bulk. In this work, we explore the conformational behavior of the drug molecule lovastatin in the crystallographically disordered solid and at crystal surfaces through a combination of computational modeling and spectroscopy. Gas-phase and periodic quantum-chemical calculations are used to study the potential energy surface associated with rotatable bonds to examine the disorder in bulk. These calculations are combined with vibrational and X-ray photoelectron spectroscopy measurements to obtain insight into the conformations in bulk and at the surface. Our MD simulations show that the bulk disorder is driven by cooperative motion of the butyl group on the $S$-butanoate moiety along one crystallographic direction beyond a unit cell. The calculations show that the $\mathrm{O}-\mathrm{H}$ group can rotate relatively freely between two low-energy conformers in the gas phase but is locked in position by intermolecular H-bonding interactions in the bulk crystal, and we find tentative spectroscopic evidence for the second conformer being present at the surface. We also comment on the relative utility of these different techniques for studying molecular conformation in bulk and at surfaces and highlight possible areas for future developments.

Keywords: lovastatin; molecular conformation; infrared spectroscopy; Raman spectroscopy; X-ray photoemission spectroscopy; density functional theory calculations; solid-state molecular dynamics

\section{Introduction}

The conformations of functional groups terminating crystal surfaces can influence important material properties including crystal morphology [1,2], wettability [3-5], dissolution rates [6] and adhesive properties [7]. These properties are often particularly important for pharmaceuticals as they affect both the downstream processing and the bioavailability of the end product [8]. Flexible molecules therefore pose a challenge both because they can present functional groups in different orientations at surfaces, and because the presence of multiple conformations in the bulk can influence intra- and intermolecular interactions, crystal packing and give rise to dynamic disorder. A holistic understanding of particle properties requires an understanding of the intrinsic conformational flexibility of the molecule and how this impacts on any bulk dynamic disorder as well as the chemical behavior of functional groups present at the crystal surfaces and the presence of impurities on the true particle surface.

Flexible molecules with multiple bond torsions are capable of forming several "conformers", defined as molecular structures with distinct topologies that correspond to 
energetic minima on the structural potential energy surface (PES) [9]. The need to understand the conformational behavior of flexible molecules has led to widespread interest in exploring the energetics associated with conformational changes, understanding the resulting polymorphism $[9,10]$, identifying spectroscopic signatures of different conformers [11-13] and applying these insights to crystal structure prediction [14]. Analysis of polymorphs in the Cambridge Structural Database (CSD) indicated that if two topologies result from a difference in a torsion angle $\Delta \theta>120^{\circ}$, they can be considered "conformational polymorphs" [9]. These conformers tend to have energy differences in the order of $10 \mathrm{kcal} \mathrm{mol}^{-1}$, undergo slow inter-conversion in solution and therefore crystallize as distinct polymorphs [15]. If, on the other hand, conformers are separated by a small energy barrier and interconvert rapidly, the conformational flexibility is not likely to affect the polymorphic outcome of a crystallization [15] and may instead lead to the presence of dynamic disorder in a solid.

The structural PES of a molecule in the gas phase can, in most cases, be mapped directly to the conformations observed in the solid state [9] and have been used to identify new conformers and to calculate spectroscopic signatures to help assign experimental data [16-20]. Rotations of, e.g., $\mathrm{CH}_{3}, \mathrm{NH}_{2}$ and $\mathrm{OH}$ groups are usually not considered during conformational analyses, as typically only a thermal average is observed from crystallography. These can, however, play a vital role in the stability of a crystal structure through "conformational adjustments" that facilitate better overall crystal packing in exchange for a small energy penalty. ${ }^{9}$ These changes can be studied using vibrational (e.g., infrared-IR) and nuclear magnetic resonance (NMR) spectroscopy [21,22], and both IR spectroscopy [23] and the NMR nuclear Overhauser effect (NOE) [21,22] have been used to study the conformations of peptides and proteins. Conformational flexibility giving rise to, e.g., molecular reorientation [24,25] and dynamic disorder [26] in organic crystals can be readily investigated using molecular dynamics (MD) simulations, while lattice dynamics modeling can predict the natural thermal motion of atoms and crystal vibrations to provide a point of reference for experimental measurements $[27,28]$. Such simulations can both help to interpret spectroscopic data [26] and provide enhanced insight into, e.g., the changes to molecular interactions that result from conformational changes due to bond torsions.

In addition to the bulk conformations, there is also the separate question of the conformation of molecules at the crystal surfaces. This is particularly important given that the functional groups exposed at the surface determine the interaction with the environment and therefore control physical properties such as adhesion [7], crystal growth [29] and dissolution rates [30].

We recently demonstrated that polarized Raman spectroscopy can be used to establish the nature and conformation of functional groups at the dominant crystal surfaces of aspirin [27]. Both IR operating in attenuated total reflection (ATR) mode using evanescent waves and Raman using long-wavelength lasers have a penetration depth of microns to $\mathrm{mm}$ in an organic crystal, and thus do not provide information about functionality present within $\mathrm{nm}$ of the surface. X-ray photoelectron spectroscopy (XPS), which typically probes the uppermost $10 \mathrm{~nm}$ of a material and can prove useful when the chemical environment at the surface, is very different to that in the bulk. XPS has, for example, previously been used to establish the conformations of polymers [31] and the protonation states of molecules in the solid state [32].

In this study, we explore the conformational flexibility of the drug molecule lovastatin. Lovastatin $\left(\mathrm{C}_{24} \mathrm{H}_{36} \mathrm{O}_{5}\right)$ is currently used to treat poroketaratosis [33] and hyperchloestrolemia and, more recently, has been explored for the treatment of hypertension. Therapeutically, lovastatin is known to lower the risk of heart disease and strokes in patients with other comorbidities [34] but has very low solubility and bioavailability. An improved understanding of the structure-property relationships in this material is therefore needed to improve its physical properties $[35,36]$ and manufacturability $[37,38]$. The lovastatin molecule has 65 atoms and eight stereogenic centers and thus can, in principle, exhibit considerable conformational flexibility. Lovastatin crystallizes into the orthorhombic space 
group $P 2{ }_{1} 2_{1} 2_{1}$ with four molecules in the unit cell $[2,39,40]$. Like its analogue simvastatin [26], lovastatin exhibits both positional and dynamic disorder of the S-butanoate arm in the bulk crystal structure [40], which was only recently resolved [2]. In the bulk, we would expect the conformational flexibility to be restricted by intra- and intermolecular interactions. Inelastic neutron scattering studies have identified the presence of stabilizing non-covalent $\mathrm{CH} \cdots \mathrm{HC}$ and $\mathrm{CH} \cdots \mathrm{O}$ interactions in the solid state, but were unable to resolve the dynamics of the O-H bond [34]. On the other hand, molecules at the surface, with fewer restricting interactions, could, in theory, exhibit a broader range of conformations.

In this work, we use a combination of quantum-chemical calculations, MD simulations and computational spectroscopy to explore the conformational flexibility of lovastatin in the gas phase and in bulk. We compare these results to measurements on crystalline powder samples using ATR-FTIR, FT-Raman and near-ambient pressure (NAP) XPS to attempt to shed light on the functional group terminations present on the crystal surface and to examine the conformation adopted by the lovastatin molecules at the true surface and the sub-surface. We also assess the possible presence of impurities from the manufacturing process.

\section{Materials and Methods}

\subsection{Experimental}

\subsubsection{Materials}

Polycrystalline lovastatin powder (>99\%) was purchased from Molekula, Durham, UK and used without further processing. The manufacturer indicates $\sim 1 \mathrm{wt} . \%$ impurities, of which $0.5 \mathrm{wt}$. \% are a related compound obtained as a side product from the synthesis.

\subsubsection{Infra-Red Spectroscopy}

IR spectra were collected using a Thermo Fischer Nicolet FTIR (UK) in attenuated total reflectance (ATR) mode through a diamond crystal $\left(650-4000 \mathrm{~cm}^{-1}, 4 \mathrm{~cm}^{-1}\right.$ resolution, 32 scans integrated per spectrum).

\subsubsection{FT-Raman Spectroscopy}

FT-Raman spectra were collected using a Bruker MultiRam (Coventry, UK) equipped with a $1064 \mathrm{~nm}$ laser and a liquid nitrogen-cooled Ge detector $\left(30-3600 \mathrm{~cm}^{-1}, 4 \mathrm{~cm}^{-1}\right.$ resolution, 4 scans integrated per spectrum). The spectra were normalized and 7-point FFT smoothing applied to remove high-frequency thermal noise from the detector.

\subsubsection{X-Ray Photoelectron Spectroscopy (XPS)}

XPS measurements were performed with a SPECS EnviroESCA (Scanwel, Bala, Gwynedd, UK) using a monochromated $\mathrm{Al} \mathrm{K}_{\alpha}$ X-ray source operating at $42 \mathrm{~W}$ and a Phoibos $150 \mathrm{NAP}$ analyzer with delay-line detector. The as-received powder was lightly pressed into a pellet and mounted with adhesive carbon tape onto an SEM stub, which was placed on the sample stage. The sample was positioned at a working distance of $\sim 300 \mu \mathrm{m}$ from the nozzle to the transfer lens stage and was illuminated with a beam spot size of $\sim 300 \mu \mathrm{m}$. Gas-phase charge compensation was achieved with 5 mbar Ar in the analysis chamber during measurements. Survey spectra were collected in 1 scan with $100 \mathrm{eV}$ pass energy, $0.5 \mathrm{eV}$ step size and $0.1 \mathrm{~s}$ dwell time, while high-resolution core-level spectra were collected in 4 scans with $20 \mathrm{eV}$ pass energy, $0.1 \mathrm{eV}$ step size and $0.4 \mathrm{~s}$ dwell time. Peak positions were charge-corrected in binding energy by aligning the aliphatic contribution to the $\mathrm{C} 1 \mathrm{~s}$ spectrum by $-2.75 \mathrm{eV}$ to $285.0 \mathrm{eV}$ and applying the same correction to all spectra. Data analysis was done with CasaXPS [41] Version 2.3.22PR1.0. Core-level spectra were fit using a GL(30) line function for all components and a linear background function. 


\subsection{Computational}

\subsubsection{Gas-Phase Conformational Analysis and Simulated Spectra}

Gas-phase optimization and conformational analysis of the lovastatin molecule was performed using the Gaussian09 code [42] with the B3LYP functional [43] and a 6-31g+(d,p) basis set [44]. This combination of functional and basis set has been reported to be a good compromise between cost and accuracy for conformational analyses [45].

As described in the text, for the conformational analyses, we investigated the three main bond torsions in the molecule, viz. the "alkyl" C-C torsion around the arm with the pyranyl ring $\left(\tau_{1}\right)$, rotation of the $\mathrm{O}-\mathrm{H}$ bond to different orientations $\left(\tau_{2}\right)$, and the "ester" $\mathrm{C}-\mathrm{O}$ torsion about the ester arm (S-butanoate group) $\left(\tau_{3}\right)$. The torsion angles about these three groups were varied over a series of fixed angles in $10^{\circ}$ steps, and all other degrees of freedom were optimized at each point. The resulting potential energy surface (PES) from each scan was then inspected to identify the global conformational minimum and three additional low-energy local minima.

The Kohn-Sham orbitals were optimized with the default tolerances of $10^{-6}$ and $10^{-8}$ a.u. on the maximum and root-mean-square (RMS) changes in the density matrix. Geometry optimizations were carried out to the default tolerances of $4.5 \times 10^{-4}$ and $3 \times 10^{-4}$ a.u. on the maximum and RMS force, and $1.8 \times 10^{-3}$ and $1.2 \times 10^{-3}$ a.u. on the maximum and RMS displacements. The default integration grids were used.

Frequency calculations were performed on the four energy minima to confirm them to be stationary points and to compute theoretical IR and Raman spectra. The Natural Atomic Orbitals (NAO) analysis was used to estimate the core atomic energy levels $E_{\mathrm{NAO}}$, which were taken as binding energies to calculate theoretical XPS spectra [46], i.e.,

$$
B E=-E_{\mathrm{NAO}}
$$

We note that this is a rather crude approximation-it assumes that $E=0$ is the vacuum level and that the photoelectron is completely ejected from the molecule, and does not take into account, e.g., electronic relaxation to stabilize the core hole. In practice, matching the binding energies to measured spectra required offsets of $\sim 11.5$ and $18 \mathrm{eV}$ for the $\mathrm{C} 1 \mathrm{~s}$ and $\mathrm{O}$ $1 \mathrm{~s}$ binding energies. Simulated spectra were obtained by convolving the individual NAO contribution with a Gaussian function with a full width at half maxima (FWHM) of $0.2 \mathrm{eV}$ to emulate typical instrument broadening, and then summing the resulting series of peak functions.

The electrostatic potentials and electron densities of the conformers were generated using Gaussian09 and visualized using the VESTA software [47]. The Multiwfn software [48] was used to study the reduced density gradients (RDGs), generated on high-quality grids with $\sim 2 \times 10^{6}$ points, to identify key intramolecular interactions. The isosurfaces were visualized using the Visual Molecular Dynamics (VMD) software [49] in conjunction with scripts provided with Multiwfn.

\subsubsection{Solid-State Molecular Dynamics and Simulated Spectra}

Periodic density functional theory (DFT) calculations were carried out using the pseudopotential plane wave approach implemented in the Vienna Ab Initio Simulation Package (VASP) code [50].

Calculations were carried out using the PBE generalized-gradient approximation (GGA) functional [51] with the DFT-D3 dispersion correction [52] (i.e., PBE+D3). The electronic structure was modeled using a plane wave basis set with a kinetic energy cutoff of $800 \mathrm{eV}$ and a $\Gamma$-centered Monkhorst-Pack $k$-point grid [53] with $3 \times 1 \times 1$ subdivisions. These settings were found through explicit convergence testing to converge the total energy and external pressure to $<1 \mathrm{meV}$ atom $^{-1}$ and $1 \mathrm{kbar}(0.1 \mathrm{GPa})$, respectively. Projector augmented wave (PAW) pseudopotentials $[54,55]$ were used to model the ion cores, with the $\mathrm{H} 1 \mathrm{~s}$ and $\mathrm{C} / \mathrm{O} 2 \mathrm{~s}$ and $2 \mathrm{p}$ electrons included in the valence shell. 
The starting point for our calculations was the most recent experimental crystal structure with the disorder components removed (CCDC identifier: CEKBEZ01) [2], which was fully optimized to tolerances of $10^{-8} \mathrm{eV}$ on the total energy and $10^{-2} \mathrm{eV} \AA^{-1}$ on the forces. With these chosen tolerances, optimization with PBE+D3 did not change the cell volume or lattice constants compared to the starting experimental structure.

To study the disorder in the solid, constant-volume Born-Oppenheimer molecular dynamics (BOMD) simulations were performed at $300 \mathrm{~K}$ in the single unit cell and a $2 \times 1 \times 1$ supercell expansion, for 100 and 25 ps, respectively. The expansion is along the short lattice vector and was chosen as a balance between system size and minimizing artefacts from periodic boundary conditions in the dynamics. The simulation temperature was controlled using a Nosé-Hoover thermostat [56] with the default coupling frequency of 40 timesteps. To speed up the simulations, the plane wave cutoff was reduced to $600 \mathrm{eV}$, the $k$-point sampling was reduced to the $\Gamma$ point, and the mass of the $\mathrm{H}$ atoms was increased to 2 (i.e., switching H for D) in order to use a larger MD timestep of $1 \mathrm{fs}$. Based on explicit convergence tests, the reduced cutoff and $k$-point sampling produce errors of $0.2 \mathrm{eV} \mathrm{molec}^{-1}\left(\sim 3 \mathrm{meV}\right.$ atom $\left.{ }^{-1}\right)$ in the total energy and $5.6 \mathrm{kbar}$ in the pressure, but lead to a negligible change in the structure, as determined by comparing the pair distribution functions.

Lattice dynamics calculations were performed on the optimized structure to obtain the $\Gamma$-point phonon frequencies using the supercell finite displacement method [57] implemented in the Phonopy code [58] and a step size of $10^{-2} \AA$. The absence of imaginary modes in these calculations confirmed that the molecules in the optimized crystal structures are at an energy minimum. The infrared and Raman activities of the modes were then computed from the eigenvectors using the Phonopy-Spectroscopy package [59]. The Born effective charge tensors and dielectric constants required to compute the IR and Raman activities were obtained using the density functional perturbation theory (DFPT) routines in VASP [60]. For the Raman activities, the dielectric constant derivatives were computed using numerical differentiation with a two-point finite difference stencil and a step size of $10^{-2} \times$ the eigenvector norm. Simulated IR and Raman spectra were generated as sums of Lorentzian peak functions using the calculated frequencies and activities and a nominal full width at half maximum (FWHM) of $10 \mathrm{~cm}^{-1}$.

During the geometry optimization and MD simulations, the PAW projection was performed in real space and the precision of the charge density grids was set automatically to avoid aliasing errors. For the MD simulation, the precision was reduced slightly to speed up the calculations. For the lattice dynamics and DFPT calculations, the PAW projection was performed in reciprocal space to ensure accurate forces, and an additional support grid with $8 \times$ as many points was used to reconstruct the augmentation charges.

\section{Results}

\subsection{Conformational Flexibility}

\subsubsection{Gas-Phase Conformational Analysis}

To investigate the conformational flexibility in lovastatin, we first carried out a set of gas-phase calculations to determine the potential energy surfaces (PESs) associated with three major rotatable bonds in the molecule (Figure 1a). A 2D version of the molecular representation can be found in Figure 1e. 

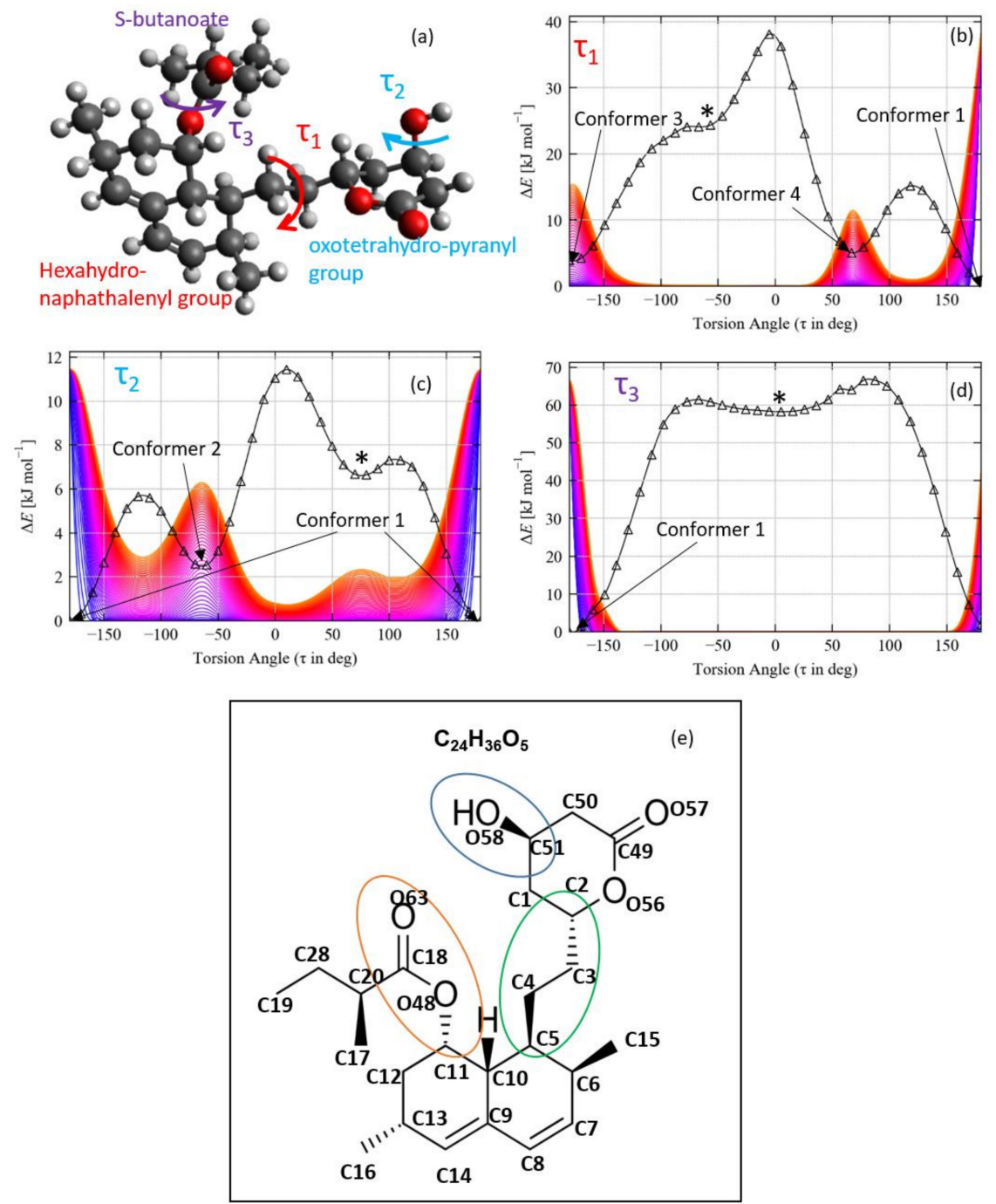

Figure 1. Gas-phase conformational analysis of the lovastatin molecule. (a) Molecular structure highlighting the three torsion angles $\tau_{1}-\tau_{3}$ investigated in the conformational analyses. (b) Potential energy surface (PES) for the "alkyl" torsion $\tau 1$ in the pyranyl group. (c) PES for the hydroxyl rotation $\tau_{2}$ in the pyranyl group. (d) PES for the "ester" torsion $\tau_{3}$ in the $S$-butanoate group. The analyses in (b)-(d) identify four low-energy conformers, which are labeled 1-4 in order of increasing energy. Three additional minima, with too high an energy to be appreciably populated at room temperature, are marked with asterisks. Plots (a)-(d) also show the occurrence probabilities of the conformations on each PES computed based on Boltzmann distributions at 100-300 K. The lines are color-coded by temperature from blue (low T) to orange (high T). (e) Molecular scheme highlighting atom labels and the three bonds rotated for the PES studies.

As can be seen in Figure 1b-d, the PES scans identify a global minimum and three new low-energy local minima. Two of the new minima were found from the alkyl torsion scan and the third from the hydroxy group orientation scan, while the ester torsion did not show any additional low-energy conformers. The four minima are identified as Conformer 1-4 on the PES scans and labeled in the order of their relative energies from lowest to highest. While we believe that the ab initio conformational analysis has identified a possible global minimum, multi-dimensional PES scan or a gas-phase MD analysis might reveal others. We believe that the present structure, being closest to that of the bulk crystal structure, however, is sufficient for the present study. The relative energies $\Delta E$ and torsion angles $\tau_{1}-\tau_{3}$ for each of the conformers are given together with other selected geometric parameters in Table 1. The PES scans also identified three additional high-energy local minima, denoted by asterisks in Figure $1 b-d$, but these are sufficiently high in energy that we would not expect them to be appreciably populated at room temperature. The PES shown in Figure $1 \mathrm{~d}$ 
also indicates a high energy barrier for the rotation of the butanoate group, as previously reported [34].

Table 1. Relative energies, occurrence probabilities at $T=290 \mathrm{~K}$, dihedrals $\tau_{1}-\tau_{3}$ and selected bond lengths and angles for the four low-energy gas-phase conformers of lovastatin identified in Figure 1.

\begin{tabular}{|c|c|c|c|c|}
\hline & Conformer 1 & Conformer 2 & Conformer 3 & Conformer 4 \\
\hline$\Delta E\left(\mathrm{~kJ} \mathrm{~mol}^{-1}\right)$ & 0 & 2.54 & 4.54 & 5.70 \\
\hline Occurrence probability $p_{n}$ at $T=290 \mathrm{~K}$ & 0.627 & 0.218 & 0.095 & 0.059 \\
\hline$\tau_{1}\left({ }^{\circ}\right)$ & 177 & 180 & 177 & 92.1 \\
\hline$\tau_{2}\left({ }^{\circ}\right)$ & -61.9 & 60.5 & 62.2 & -61.3 \\
\hline$\tau_{3}\left({ }^{\circ}\right)$ & 0.4 & -2.0 & -2.9 & 3.8 \\
\hline$\Phi(\mathrm{C} 19-\mathrm{C} 28-\mathrm{C} 20-\mathrm{C} 17)\left(\right.$ butyl) $\left(^{\circ}\right)$ & 66.0 & 66.1 & 66.0 & 66.8 \\
\hline$\Phi(\mathrm{C} 10-\mathrm{C} 28-\mathrm{C} 20-\mathrm{C} 17)$ (butyl, hexahydronaphthenyl) $\left(^{\circ}\right)$ & -172.3 & -167.3 & -167.6 & -165.1 \\
\hline$\Phi(\mathrm{O} 48-\mathrm{C} 11-\mathrm{C} 5-\mathrm{C} 4)$ (between S-butanoate/pyrnyl groups) $\left(^{\circ}\right)$ & 90.7 & 91.2 & 90.3 & 92.1 \\
\hline$d(\mathrm{C}=\mathrm{O})(S$-butanoate $)(\AA)$ & 1.217 & 1.217 & 1.217 & 1.216 \\
\hline$d(\mathrm{C}-\mathrm{O})(S$-butanoate $)(\AA)$ & 1.352 & 1.351 & 1.352 & 1.357 \\
\hline$d(\mathrm{C}=\mathrm{O})($ pyranyl) $(\AA)$ & 1.211 & 1.210 & 1.211 & 1.212 \\
\hline$d(\mathrm{C}-\mathrm{O})$ (pyranyl) $(\AA)$ & 1.353 & 1.357 & 1.353 & 1.351 \\
\hline$d(\mathrm{O}-\mathrm{H})$ (pyranyl) $(\AA)$ & 0.966 & 0.967 & 0.966 & 0.966 \\
\hline
\end{tabular}

While we found no significant differences in the bond lengths between the four conformers, each has distinctly different dihedral angles. The alkyl torsion $\tau_{1}$ represents the angle that the pyranyl group makes with the hexahydronaphathenyl group. The global minimum Conformer 1 has a near-identical dihedral to Conformer 3, and the major difference between them is the angle that the butyl group makes with the hexahydronaphththenyl group $(\Phi(C 10-C 28-C 20-C 17))$. The $\tau_{1}$ dihedrals of Conformers 2 and 3 differ by only $2^{\circ}$ but the hydroxyl group is rotated by $180^{\circ}\left(\tau_{2}\right)$. In Conformer 4 , the $\tau_{1}$ dihedral is $\sim 90^{\circ}$ smaller than the other conformers, which results in the $S$-butanoate and the pyranyl groups running parallel to each other. An overlay of the structures of the four low-energy conformers and a molecule extracted from the experimental crystal structure can be found in Figure S1 (Supplementary Materials).

Given the relative energies $\Delta E_{n}$ of the $n=4$ conformers, the occurrence probability $P_{n}$ at a temperature $T$ can be obtained from the expression:

$$
P_{n}(T)=\frac{1}{Z(T)} \exp \left[-\Delta E_{n} / k_{\mathrm{B}} T\right]=\frac{\exp \left[-\Delta E_{n} / k_{\mathrm{B}} T\right]}{\sum_{n} \exp \left[-\Delta E_{n} / k_{\mathrm{B}} T\right]}
$$

where $k_{\mathrm{B}}$ is the Boltzmann constant and $Z(T)$ is the thermodynamic partition function. At $298 \mathrm{~K}$, this analysis predicts that $62 . \%$ of a sample of isolated lovastatin molecules would adopt Conformer 1, 21.8\% would adopt Conformer 2, which is $2.54 \mathrm{~kJ} \mathrm{~mol}^{-1}$ higher in energy, and a much smaller 9.5 and $5.9 \%$ would adopt Conformers 3 and 4 due to their higher relative energies of 4.54 and $5.70 \mathrm{~kJ} \mathrm{~mol}^{-1}$, respectively. We would therefore expect the main flexibility in the molecule to be around the orientation of the $\mathrm{OH}$ group and the secondary butyl group. Previous studies [34] using inelastic neutron scattering and solid-state NMR suggested that the main contributions to the spectroscopic features are from methyl dynamics, however, but were unable to resolve the $\mathrm{OH}$ dynamics. As shown in the PES scans in Figure 1, the occurrence probabilities of the higher-energy conformers are very strongly temperature-dependent. Excepting the $\mathrm{OH}$ group rotation $\tau_{2}$, the bond torsion listed in Table 1 also does not suggest any angle change greater than $120^{\circ}$, which explains why lovastatin does not show conformational polymorphism [9]. 


\subsubsection{Solid-State Molecular Dynamics}

To investigate the conformational flexibility giving rise to the dynamic disorder in bulk lovastatin, we first performed short MD simulations at $300 \mathrm{~K}$ on the lovastatin unit cell and a $2 \times 1 \times 1$ supercell expansion (Figure 2). Plotting the total energy, temperature, cell pressure and root-mean-square displacement (RMSD) over the two trajectories confirms that the 100 and 25 ps simulation times for the two models were sufficient to reach equilibration (Figures S2-S5).
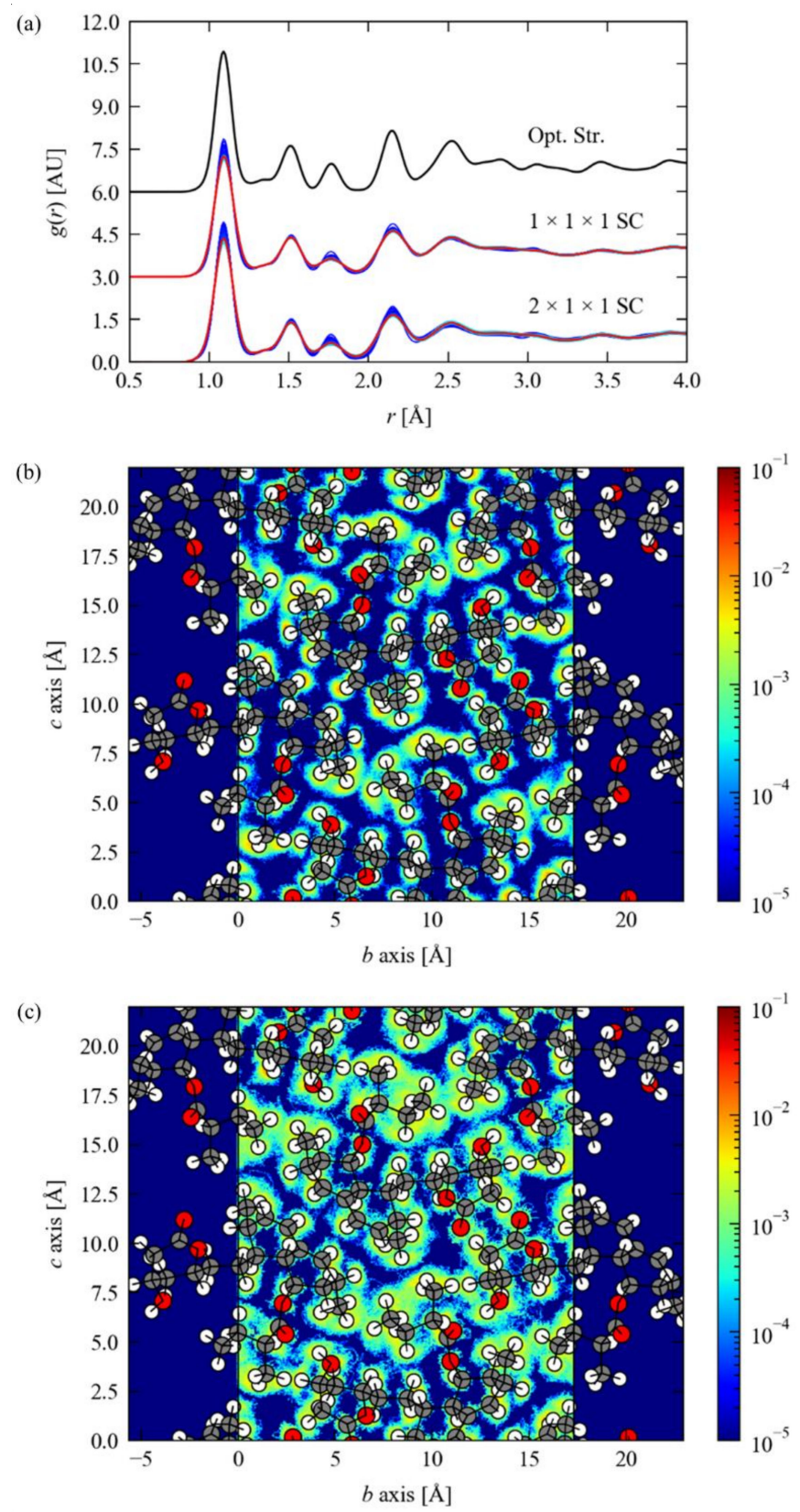

Figure 2. Molecular dynamics simulation of the lovastatin crystal. (a) Comparison of the pair distribution functions $g(r)$ of the optimized crystal structure (top) and averaged over the MD trajectories run with a single unit cell and in a $2 \times 1 \times 1$ supercell (middle/bottom). For each of the MD trajectories, the average $g(r)$ is shown in red, and functions averaged over smaller time windows of 500/100 ps are shown as colored lines from blue to cyan. The PDFs were generated using a Gaussian broadening with a nominal linewidth $\sigma$ of $0.05 \AA$. (b)/(c) Histograms of the atomic positions in the single-cell (b) and supercell (c) models projected onto the $b c$ plane, with the atomic positions in the optimized structure overlaid as balls and sticks for comparison. 
The static (optimized) structure and the dynamic structures during the MD simulations were compared by computing the pair distribution functions (PDFs) $g(r)$ (Figure 2a). The $g(r)$ are calculated for a given structure according to [61]:

$$
g(r)=\frac{1}{4 \pi \rho \Delta r} \frac{1}{N} \sum_{i=1}^{N} \sum_{j=1}^{N} \frac{\delta\left(r-r_{i j}\right)}{r_{i j}^{2}}
$$

where $N$ is the number of atoms, $\rho=N / V$ is the atomic number density, the double sum runs over atomic pairs $i$ and $j$ separated by a distance $r_{i j}$ and the bond distances are accumulated into a histogram with a bin width $\Delta r$. The $g(r)$ expresses the probability of finding an atom at a distance $r$ from a reference atom relative to that expected for a homogenous distribution at the average atomic density. Peaks in the $g(r)$ thus indicate preferred interatomic distances.

In the optimized lovastatin crystal, the complex molecular structure results in sharp features at $1.1,1.5,1.8,2.2$ and $2.6 \AA$, corresponding to five distinct neighbor distances. Comparing the PDFs of the optimized structure to those averaged over the two MD simulations appears to show only thermal broadening, and does not provide any direct evidence for significant conformational changes that might show up, e.g., as shoulder features. Comparison of PDFs averaged over shorter time windows again confirms rapid structural equilibration from the initial model.

We further examined the thermal motion by computing histograms of the atomic positions projected along the crystallographic $b$ and $c$ axes over the two trajectories (Figure 2b,c). Comparison of the two plots suggests a considerably larger range of thermal motion in the trajectory run with the larger supercell, despite there being little evidence for changes in the local structure in the PDFs. The supercell is expanded along the short crystallographic $a$ axis, so we infer from this that the motion of adjacent molecules along this direction is correlated such that movement of a molecule in one unit cell facilitates movement of molecules in the neighboring cells.

We also measured a set of dihedral angles and bond lengths describing the conformation of a representative molecule in each trajectory over the simulation, using the Visual Molecular Dynamics (VMD) software [49]. We measured the $\tau_{1}-\tau_{3}$ dihedrals investigated in the gas-phase conformational analyses (c.f. Figure 1a) together with an angle quantifying the orientation of the butyl group on the S-butanoate moiety. We also tracked the O-H $\cdots \mathrm{O}$ $\mathrm{H}$-bond length and an angle defining the $\mathrm{O}-\mathrm{H}$ group orientation. These data are shown in Figures S6-S8.

While we do observe some thermal variation in the $\tau_{1}-\tau_{3}$ dihedrals during the simulations, they oscillate about an average value. There is, however, clear evidence for the butyl group adopting two distinct conformations over the two trajectories, suggesting that this is the most flexible part of the molecule in the solid state, as suggested by inelastic neutron scattering data [34]. We observe two conformational changes in the 100 ps trajectory of the single unit cell, and one conformational change during the 25 ps trajectory of the supercell. The higher frequency of changes in the larger supercell may again be taken as evidence that these conformational changes are enabled by cooperative movements of molecules along the $a$ direction, in keeping with the histogram plots in Figure $2 \mathrm{~b}, \mathrm{c}$. However, conformational changes are inherently stochastic, so this conclusion should be treated with caution given the short simulation times.

Based on the gas-phase calculations, we would expect also to see changes in the orientation of the O-H group. However, our analysis of the MD trajectories shows that the $\mathrm{O}-\mathrm{H}$ group has a strong preference for remaining in one orientation, with changes in the torsion angle and the $\mathrm{O}-\mathrm{H}$. . O H-bond distance suggest regular, unsuccessful attempts at reaching the rotated conformer. This is likely due to the intermolecular H-bond formed in the solid state, which is not present in the gas-phase models, adjusting the PES for the rotation. We also used the H-bond analysis routine in VMD to count the number of H-bond interactions in the simulation cell using a distance cutoff of $3 \AA$ (Figure S9). 
This shows that the smaller single-cell model generally has one H-bond per molecule, i.e., all bonds are saturated, whereas the larger supercell model generally has slightly less than one $1 \mathrm{H}$-bond per molecule. This suggests that, as for the butyl conformation, the dynamics of molecules in neighboring unit cells along the shorter $a$ direction may enable some additional conformational flexibility around the O-H group.

It is, of course, also possible that our simulation is simply not long enough to observe conformational changes. Assuming that a conformational change can be modeled as a firstorder reaction, the number of events $n$ per unit time can be estimated from the Arrhenius equation as:

$$
n=A \exp \left[-E_{A} / R T\right]
$$

where $A$ is the attempt frequency, $E_{A}$ is the activation energy and $R$ is the gas constant. The gas-phase conformational analyses discussed in the following section suggest energy barriers of between $6 \mathrm{~kJ} \mathrm{~mol}^{-1}$ for rotation of the $\mathrm{OH}$ group to $60 \mathrm{~kJ} \mathrm{~mol}^{-1}$ for the rotation of the $S$-butanoate about the $\mathrm{C}-\mathrm{O}$ bond (c.f. Figure 1). If one assumes that the conformational changes are driven by vibrations with a "ballpark" frequency of $1000 \mathrm{~cm}^{-1}(30 \mathrm{THz})$, the corresponding values of $n$ would range from 2.7 to $10^{-9} \mathrm{ps}^{-1}$. We might therefore expect to see the low-energy $\mathrm{OH}$ conformational change many times during the simulation, but we would need to simulate for at least nine orders of magnitude longer (i.e., milliseconds) to see the $S$-butanoate conformation change, if this motion is indeed possible in the solid state. The fact that we do not see evidence for complete $\mathrm{OH}$ rotation, in either of the supercells, again strongly suggests that the activation energy may be significantly higher in the solid state than in the gas phase.

\subsubsection{Intramolecular Interactions}

Lovastatin is a large molecule with a range of possible torsions in the side chains, which can result in different types of intramolecular interactions in different conformers.

Analysis of the electrostatic potentials (ESPs) of the low-energy conformers identified from the gas-phase PES scans shows that all four show subtle electrostatic interactions between the $\mathrm{S}$-butanoate $\mathrm{C}-\mathrm{O}$ oxygen and the $\mathrm{C}-\mathrm{OH}$ oxygen on the pyranyl group with $\mathrm{H}$ atoms on adjacent $\mathrm{C}$ atoms (Figure S10).

We also studied the non-covalent interactions (NCI) in the four conformers from the sign of the reduced density gradient (RDG; Figure 3). The isosurfaces in Figure 3 are colored based on the sign of the second derivative of the electron density (the Laplacian) such that blue indicates H-bonding interactions (-ve Laplacian), green indicates van der Waals (vdW) interactions (Laplacian close to zero), and red indicates steric interactions (+ve Laplacian). The four conformers show an increase in vdW interactions (indicated by green isosurfaces) between the $S$-butanoate and pyranyl groups with increasing conformer energy. This relates directly to the smaller $\tau_{1}$ dihedral in Conformer 4 , as noted above. There are also increased vdW interactions between the butyl group of the $S$-butanoate and the hexahydronaphathaenyl group in Conformer 4.

Taken together, these results show that the conformational PES of lovastatin is governed mainly by vdW interactions and does not have a strong electrostatic interaction that preferentially stabilizes the higher-energy conformations or results in any particular intramolecular configurations being "locked in", as is observed in some organic molecules [62]. 


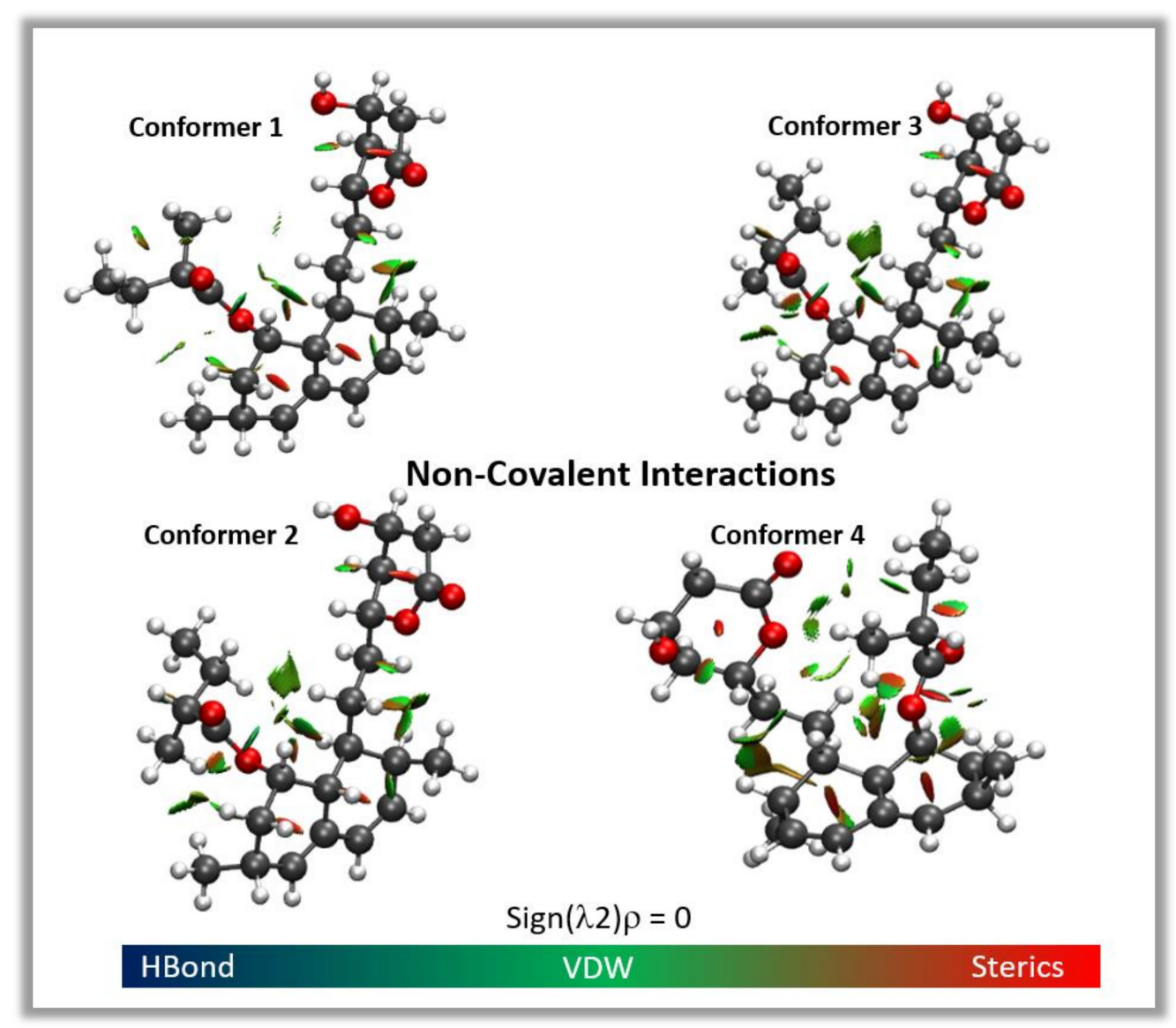

Figure 3. Non-covalent interaction (NCI) plots for the four low-energy conformers of lovastatin identified from the potential energy surface (PES) scans shown in Figure 1. The isosurfaces are drawn at a contour value of 0.05 and are colored using the sign of the Laplacian. Blue represents H-bonding interactions (-ve Laplacian), green indicates van der Waals (vdW) interactions (Laplacian close to zero), and red indicates steric interactions (+ve Laplacian). These images were prepared using the Multiwfn [48] and VMD programs [49].

\subsection{Vibrational Spectroscopy}

The $P 2{ }_{1} 2_{1} 2_{1}$ space group has the $222\left(D_{2}\right)$ point group with four irreducible representations (irreps), viz. A, $B_{1}, B_{2}$ and $B_{3}$ (Table S1) [63]. Of these, all four may be Raman-active, and the three $B$ irreps may also be IR-active. Ignoring the zero-frequency acoustic modes, the four molecules in the unit cell result in $3 n_{a}-3=777$ vibrations, which span an irreducible representation of $195 \mathrm{~A}+194 \mathrm{~B}_{1}+194 \mathrm{~B}_{2}+194 \mathrm{~B}_{3}$ at the $\Gamma$-point. Therefore, as previously reported [34], we anticipate up to 582 IR-active vibrations and 777 Raman-active vibrations, which suggests that both types of spectroscopy could potentially provide rich information about the conformations of molecules in the bulk crystal and at the crystal surfaces, as well as information on functional group terminations at the crystal surfaces.

\subsubsection{IR Spectroscopy}

The IR spectrum collected from lovastatin powder is shown in Figure 4 together with the solid-state spectrum from lattice dynamics modeling and the simulated spectra of each of the four low-energy conformers identified in the gas-phase PES scans. 

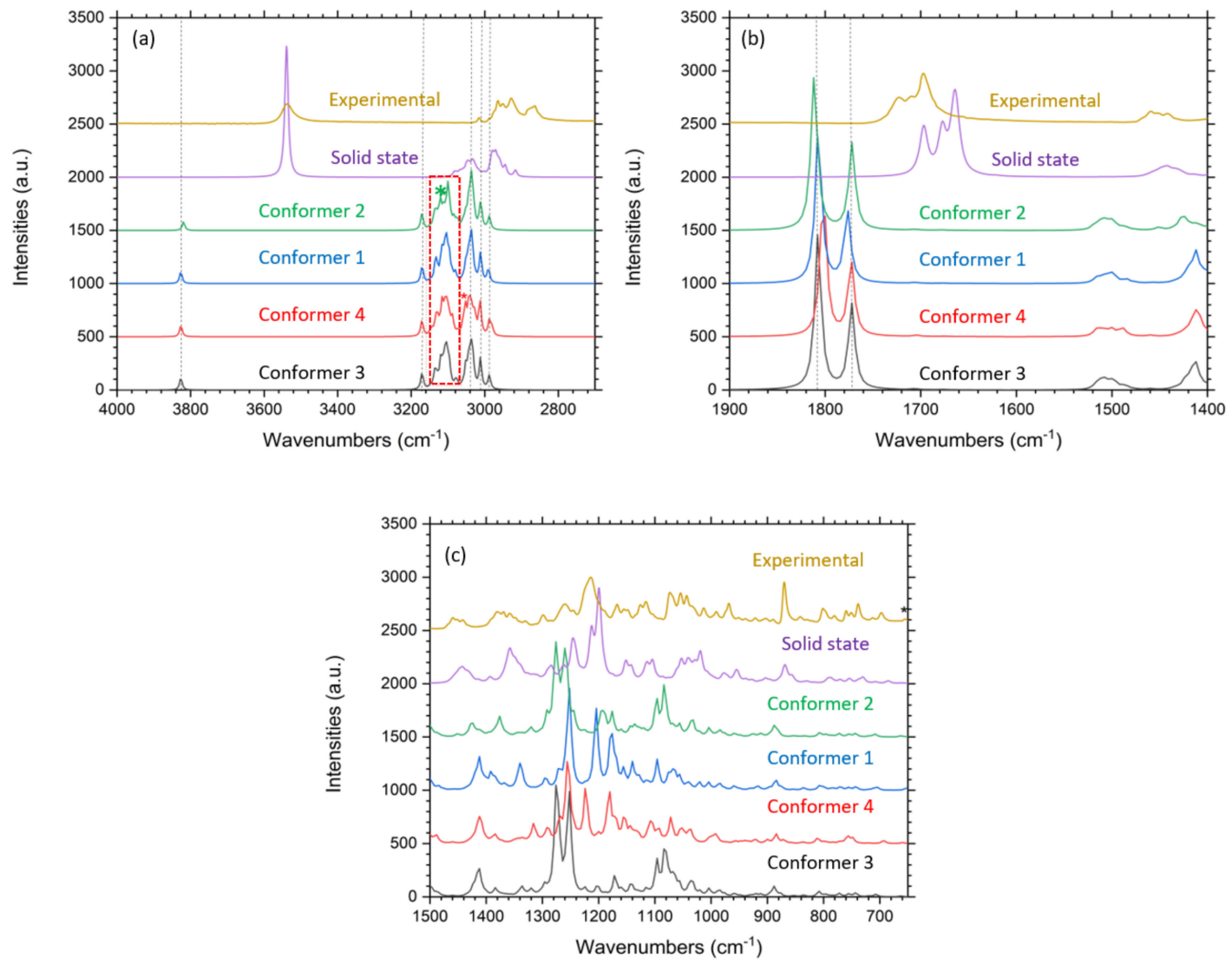

Figure 4. Comparison of the infrared (IR) spectra of lovastatin powder (yellow) to the calculated spectrum of the solid (purple) and the gas-phase spectra of the four low-energy conformers identified from the gas-phase potential energy surface (PES) scans in Figure 1 (blue, green, black, red). The spectra are shown in three separate regions, viz. $2700-4000 \mathrm{~cm}^{-1}$ (a), 1400-1900 $\mathrm{cm}^{-1}$ (b) and 650-1500 $\mathrm{cm}^{-1}$ (c). The vertical black lines in (a) and (b) highlight differences in the position of peaks among the gas-phase conformers with respect to the lowest-energy Conformer 1 . The red box in (a) indicates the changes in the C-H stretching in the four low-energy conformers. All six sets of spectra have been adjusted to similar intensity scales.

In general, our measurements broadly agree with those reported in the literature [36], and a full set of tentative assignments [64] can be found in Table 2 .

The solid-state spectrum from lattice dynamics calculations is a good match with the experimental spectrum, especially at low wavenumbers, although there is a notable shift in the bands in the $\mathrm{C}-\mathrm{H}$ and $\mathrm{C}=\mathrm{O}$ regions. These wavenumber-dependent shifts may be due either to a systematic error in the predicted frequencies, or to the fact that the single optimized geometry that we performed the calculations on does not accurately reflect the positional disorder in the crystal.

The calculated vibrational frequencies of the gas-phase conformers are generally higher than those obtained from the solid-state calculations, which may be ascribed to the intermolecular interactions present in the solid-state model but absent in the gasphase calculations-for example, the observed $\mathrm{H}$-bonding and the $\mathrm{CH} \cdots \mathrm{HC}$ and $\mathrm{CH} \cdots \mathrm{O}$ interactions [34]. In the measured spectrum, the pyranyl group $\mathrm{C}=\mathrm{O}$ vibration occurs at $1724 \mathrm{~cm}^{-1}, 10 \mathrm{~cm}^{-1}$ higher than the $S$-butanoate $\mathrm{C}=\mathrm{O}$ due to the effect of the ring strain. These vibrations are predicted at $50-70 \mathrm{~cm}^{-1}$ higher wavenumbers in the gasphase calculations, which we again ascribe to the absence of intermolecular H-bonding. Similarly, coupled C-O stretches at $1500 \mathrm{~cm}^{-1}$ in the gas-phase models appear at much lower wavenumbers between 1050 and $1150 \mathrm{~cm}^{-1}$ in the solid state, again due to constraints imposed by intermolecular H-bonding. The $\mathrm{C}=\mathrm{C}$ symmetric stretching associated with the diene functionality on the hexahydronaphthenyl group appears in the experimental 
spectrum as an intense band at $1698 \mathrm{~cm}^{-1}$. The solid-state calculation predicts a similar intensity pattern, while the gas-phase spectra predict a very low intensity, which suggests that interactions between hexahydronaphthenyl groups on adjacent lovastatin molecules in the solid state give rise to appreciable changes in dipole moment. The presence of very weak C-H overtone bands at $2173 \mathrm{~cm}^{-1}$, together with the presence of vdW interactions suggested by the NCI analysis, is further confirmation for the $\mathrm{CH}$... HC interactions previously suggested using INS studies [34].

Table 2. Tentative IR peak assignments for the reference experimental spectrum and the simulated spectra of solid-state lovastatin and the four low-energy gas-phase conformers identified from the PES scan. Abbreviations: sh-shoulder, w-weak, vw-very weak.

\begin{tabular}{|c|c|c|c|c|c|c|}
\hline Solid-State & Experimental & $\begin{array}{c}\text { Tentative } \\
\text { Assignment }\end{array}$ & $\begin{array}{l}\text { Conformer } 1 \\
\text { (Gas Phase) }\end{array}$ & $\begin{array}{l}\text { Conformer } 2 \\
\text { (Gas Phase) }\end{array}$ & $\begin{array}{l}\text { Conformer } 3 \\
\text { (Gas Phase) }\end{array}$ & $\begin{array}{l}\text { Conformer } 4 \\
\text { (Gas Phase) }\end{array}$ \\
\hline- & 655 & $\begin{array}{l}\text { O-H out-of-plane } \\
\text { deformation }\end{array}$ & 652 & 656 & - & - \\
\hline $\begin{array}{c}790(\mathrm{br}, \mathrm{w}), 730(\mathrm{br}, \\
\text { w) }\end{array}$ & $\begin{array}{c}698,714(\mathrm{w}), 739 \\
752,760,782,796 \\
\quad(\mathrm{sh}), 802\end{array}$ & $\begin{array}{l}\text { C-H out-of-plane } \\
\text { deformation in } \\
\text { conjugated } \\
\text { vinylenes }\end{array}$ & $\begin{array}{c}808,784,756,744 \\
704\end{array}$ & $\begin{array}{c}808,772,756,744 \\
708\end{array}$ & $\begin{array}{l}808,796,772,756 \\
\quad 744,708\end{array}$ & $812,756,748,692$ \\
\hline $870(\mathrm{br}, \mathrm{w})$ & $\begin{array}{c}833(w), 841(w), \\
870\end{array}$ & $\begin{array}{l}\text { Aliphatic } \mathrm{C}-\mathrm{CH}_{3} \\
\text { stretches }\end{array}$ & 876 (sh), 836 & - & 876 & 872 \\
\hline $976(w), 966(w)$ & $\begin{array}{l}890,903,923,939 \\
(w), 950(w), 968\end{array}$ & $\begin{array}{l}\text { Out-of-plane C-H } \\
\text { deformation in cis } \\
\text { vinylenes }\end{array}$ & $\begin{array}{c}960,916,896(\mathrm{sh}) \\
884\end{array}$ & $\begin{array}{c}976(\mathrm{w}), 960(\mathrm{w}) \\
928,912,888\end{array}$ & $\begin{array}{c}976,960,920(w), \\
888\end{array}$ & $924,900,884$ \\
\hline $1063,1051,1031$ & $\begin{array}{c}990,1014,1028, \\
1033 \text { (sh), 1043, } \\
1054\end{array}$ & $\begin{array}{l}\text { Aliphatic C-H } \\
\text { deformation }\end{array}$ & $\begin{array}{c}1156,1140,1128, \\
1112,1096,1076, \\
1068,1056,1040, \\
1020,1004,984\end{array}$ & $\begin{array}{c}1144,1136,1124 \\
(w), 1120,1096, \\
1084,1068(w), \\
1056,1036,1032, \\
1020(w), 1004,984\end{array}$ & $\begin{array}{c}1116,1096,1084 \\
1068 \text { (sh), } 1056 \text { (sh), } \\
1036,1020,1004 \\
988,984\end{array}$ & $\begin{array}{c}1108,1092,1072, \\
1056,1036,1004, \\
992\end{array}$ \\
\hline $1149,1115,1105$ & $\begin{array}{c}\text { 1074, 1080, 1107, } \\
\text { 1111, 1115, 1126, } \\
1153\end{array}$ & $\begin{array}{l}\text { Coupled C-O } \\
\text { stretches }\end{array}$ & $1340(\mathrm{~s}), 1368(\mathrm{w})$ & 1376 (s), 1340 (br), & 1320,1336 & $1340(\mathrm{br}), 1372(\mathrm{w})$ \\
\hline 1210 (sh), 1199 & $1168,1193,1215$ & $\begin{array}{l}\text { Asymmetric } \\
\text { C-O-C stretching }\end{array}$ & $\begin{array}{c}1224(\mathrm{vw}), 1204(\mathrm{~s}), \\
1180(\mathrm{sh}), 1176, \\
1168(\mathrm{sh})\end{array}$ & $\begin{array}{c}1224(\mathrm{w}), 1194(\mathrm{~s}) \\
1176,1160(\mathrm{w})\end{array}$ & $\begin{array}{l}1224(\mathrm{w}), 1200(\mathrm{w}) \\
1172,1160(\mathrm{sh})\end{array}$ & $\begin{array}{l}1224(\mathrm{~s}), 1200(\mathrm{w}), \\
1180,1172(\mathrm{sh})\end{array}$ \\
\hline $\begin{array}{l}1285 \text { (br), } 1264 \text { (br, } \\
\text { sh), } 1246 \text { (br) }\end{array}$ & $\begin{array}{l}1246,1261,1297 \\
1329,1360,1369\end{array}$ & $\begin{array}{l}\text { In-plane O-H } \\
\text { deformation and } \\
\text { symmetric C-H } \\
\text { deformation }\end{array}$ & $1272,1252,1296$ & $\begin{array}{l}1320,1292,1276, \\
1260,1244(\mathrm{sh})\end{array}$ & $1276,1252,1296$ & $\begin{array}{l}1248 \text { (sh), 1268, } \\
1256,1292,1316,\end{array}$ \\
\hline \multirow[t]{2}{*}{$1395(\mathrm{w}), 1442(\mathrm{br})$} & 1382,1444 & $\begin{array}{l}\text { In-plane O-H } \\
\text { deformation } \\
\text { coupled with C-H } \\
\text { wagging }\end{array}$ & $\begin{array}{c}1420(\mathrm{sh}), 1412 \\
1384,1392\end{array}$ & $\begin{array}{c}1452,1428,1424 \\
1412 \text { (sh), } 1384 \text { (br, } \\
\text { sh) }\end{array}$ & $\begin{array}{c}1424 \text { (sh), } 1412, \\
1384\end{array}$ & $\begin{array}{c}1424(\mathrm{sh}), 1412, \\
1384\end{array}$ \\
\hline & 1455,1461 & $\begin{array}{l}\text { Asymmetric C-H } \\
\text { deformation }\end{array}$ & $1516,1500,1484$ & $\begin{array}{l}1520(\mathrm{sh}), 1508, \\
1500,1488(\mathrm{sh})\end{array}$ & 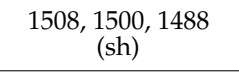 & $1516,1500,1488$ \\
\hline 1664 & 1698 & $\begin{array}{c}\mathrm{C}=\mathrm{C} \text { symmetric } \\
\text { stretching in } \\
\text { dienes }\end{array}$ & $1677,1706(\mathrm{vw})$ & $1677,1706(\mathrm{vw})$ & 1677, $1707(\mathrm{vw})$ & $1675,1704(\mathrm{vw})$ \\
\hline 1697,1677 (sh) & 1711,1724 & $\begin{array}{c}\mathrm{C}=\mathrm{O} \text { in esters and } \\
\text { secondary amides } \\
\text { (also seen in thiol } \\
\text { esters) }\end{array}$ & 1808,1776 & 1812,1772 & 1808,1772 & 1800,1772 \\
\hline- & $2173(w)$ & C-H overtones & - & - & - & - \\
\hline- & $\begin{array}{c}2323(\mathrm{w}), 2343(\mathrm{w}) \\
2362(\mathrm{w})\end{array}$ & $\begin{array}{l}\text { Free } \mathrm{S}-\mathrm{H} \\
\text { stretching? }\end{array}$ & - & - & - & - \\
\hline $2972,2942,2918$ & $\begin{array}{l}2989(\mathrm{sh}), 2966, \\
2950,2930,2864\end{array}$ & $\begin{array}{l}\text { Aliphatic } \mathrm{C}-\mathrm{H} \\
\text { stretching } \\
\text { (symmetric and } \\
\text { asymmetric in } \\
\mathrm{CH}_{2} \text { and } \mathrm{CH}_{3} \text { ) }\end{array}$ & $\begin{array}{l}3052 \text { (sh), } 3036 \\
3012,2992\end{array}$ & $\begin{array}{l}3048(\mathrm{sh}), 3036 \\
3012,2988\end{array}$ & $\begin{array}{l}3052(\mathrm{sh}), 3036 \\
3012,2988\end{array}$ & $\begin{array}{c}3052(\mathrm{~s}), 3040,3012, \\
2988\end{array}$ \\
\hline 3079,3041 (s, br) & $3014,3048(w)$ & $\begin{array}{l}\text { Olefinic C-H } \\
\text { stretching }\end{array}$ & $\begin{array}{l}3172,3132,3116, \\
3112 \text { (sh), 3104, } \\
3096 \text { (sh), } 3080\end{array}$ & $\begin{array}{c}3172,3136,3120, \\
3112(\mathrm{sh}), 3100, \\
3084(\mathrm{w}), 3072(\mathrm{sh})\end{array}$ & $\begin{array}{c}3172,3132,3120 \\
3104,3080\end{array}$ & $\begin{array}{c}\text { 3172, 3144, 3128, } \\
3116,3104,3088, \\
3072(w)\end{array}$ \\
\hline 3538 & 3538 & $\begin{array}{l}\text { O-H stretching } \\
\text { (with } \\
\text { intermolecular } \\
\text { H-bonding) }\end{array}$ & 3824 & 3820 & 3824 & 3824 \\
\hline
\end{tabular}


Finally, weak features at $2323,2343,2362 \mathrm{~cm}^{-1}$ may suggest the presence of impurities with free thiol groups (Figure S12). This is consistent with the $\sim 0.5 \mathrm{wt}$. \% of impurities indicated by the manufacturer, which could include the S-H-containing malonyl-CoA molecule [37]. The acid form of lovastatin is also known to sometimes be present as an impurity [65], but we see no evidence for the presence of carboxylic acid monomers or dimers in our measured spectra. There could also be a contribution to the $\mathrm{C}=\mathrm{C}$ symmetric stretch region of the spectrum from $\mathrm{C}=\mathrm{N}$ vibrations of in malonyl-CoA impurities.

Having confirmed good agreement between the measurements and the simulated IR spectrum of bulk lovastatin, we proceeded to compare our measurements to the calculated spectra of the gas-phase conformers, to identify features that may signify differences in the conformation of surface molecules.

The (110) and (020) crystal faces of lovastatin could potentially expose the O-H and olefinic groups of the hexahydronaphthenyl moiety [2], depending on the choice of solvent and preparation method. The solid-state calculations predict a sharp O-H stretch at $3538 \mathrm{~cm}^{-1}$, whereas the corresponding feature in the $\mathrm{O}-\mathrm{H}$ stretch region of the experimental spectrum is broader and less intense. This can be ascribed to the variable $\mathrm{H}$-bond strength between the $\mathrm{O}-\mathrm{H}$ with $\mathrm{C}=\mathrm{O}$ bond on the $\mathrm{S}$-butanoate group in bulk, as well as to surface groups in potentially different chemical environments. Of the four gas-phase conformers, Conformers 1, 3 and 4 have the $\mathrm{O}-\mathrm{H}$ group in a similar orientation to molecules in bulk, whereas in Conformer 2, the bond is rotated by $180^{\circ}$. This is predicted to shift the $\mathrm{O}-\mathrm{H}$ peak by $4 \mathrm{~cm}^{-1}$ in the gas phase compared to the other conformers, despite a negligible $10^{-3} \AA$ change in the bond length. Since the $\mathrm{O}-\mathrm{H}$ feature in the experimental spectrum is considerably broader than this difference, we cannot discount the presence of Conformer 2 on the surface based on this peak position alone. Furthermore, the intensity patterns of the peaks in the C-H stretching region between 3000 and $3200 \mathrm{~cm}^{-1}$, which contains olefinic $\mathrm{C}-\mathrm{H}$ and terminal $\mathrm{CH}_{3}$ stretches, are notably different between the measured and simulated solid-state spectrum, even taking into account the nominal line broadening $\left(10 \mathrm{~cm}^{-1}\right)$ used in the latter. The intensity pattern in the experimental spectrum is, however, very similar to those predicted for the gas-phase Conformer 2 (marked by the green asterisk inside the red box in Figure 4a), which supports appreciable amounts of this conformer being present at the surface.

The lower-wavenumber C-H stretches at $2988 \mathrm{~cm}^{-1}$ and $2992 \mathrm{~cm}^{-1}$ in the gas-phase conformers correspond to $\mathrm{C}-\mathrm{H}$ stretches on the hexahydronaphathenyl group (C10 in Figure 1e), suggesting that hexahydronaphthenyl groups may be exposed at the surface, as indicated by the olefinic C-H stretches as well. These bands are present in the experimental spectrum but not in the calculated solid-state spectrum, which suggests that hexahydronaphthenyl groups may be exposed at the surface.

The frequency and intensity pattern of the in-plane $\mathrm{O}-\mathrm{H}$ and symmetric $\mathrm{C}-\mathrm{H}$ deformations, which occur at 1246, 1261, 1297, 1329, 1360 and $1369 \mathrm{~cm}^{-1}$ in both the experimental and simulated solid-state spectra, are also very similar to the gas-phase spectrum of Conformer 2. The experimental spectra also show $\mathrm{O}-\mathrm{H}$ out-of-plane deformations at $655 \mathrm{~cm}^{-1}$, which are predicted at $656 \mathrm{~cm}^{-1}$ in the Conformer 2 spectrum but at $652 \mathrm{~cm}^{-1}$ in Conformer 1 . This provides further evidence for the possible presence of Conformer 2 on the exposed crystal surfaces, or at least indicates that we cannot discount this possibility based on the spectroscopy.

\subsubsection{Raman Spectroscopy}

The Raman spectrum of lovastatin powder is shown in Figure 5 alongside the calculated solid-state spectrum and the calculated spectra of the four low-energy gas-phase conformers. A full set of tentative assignments [64] can be found in Table 3. 

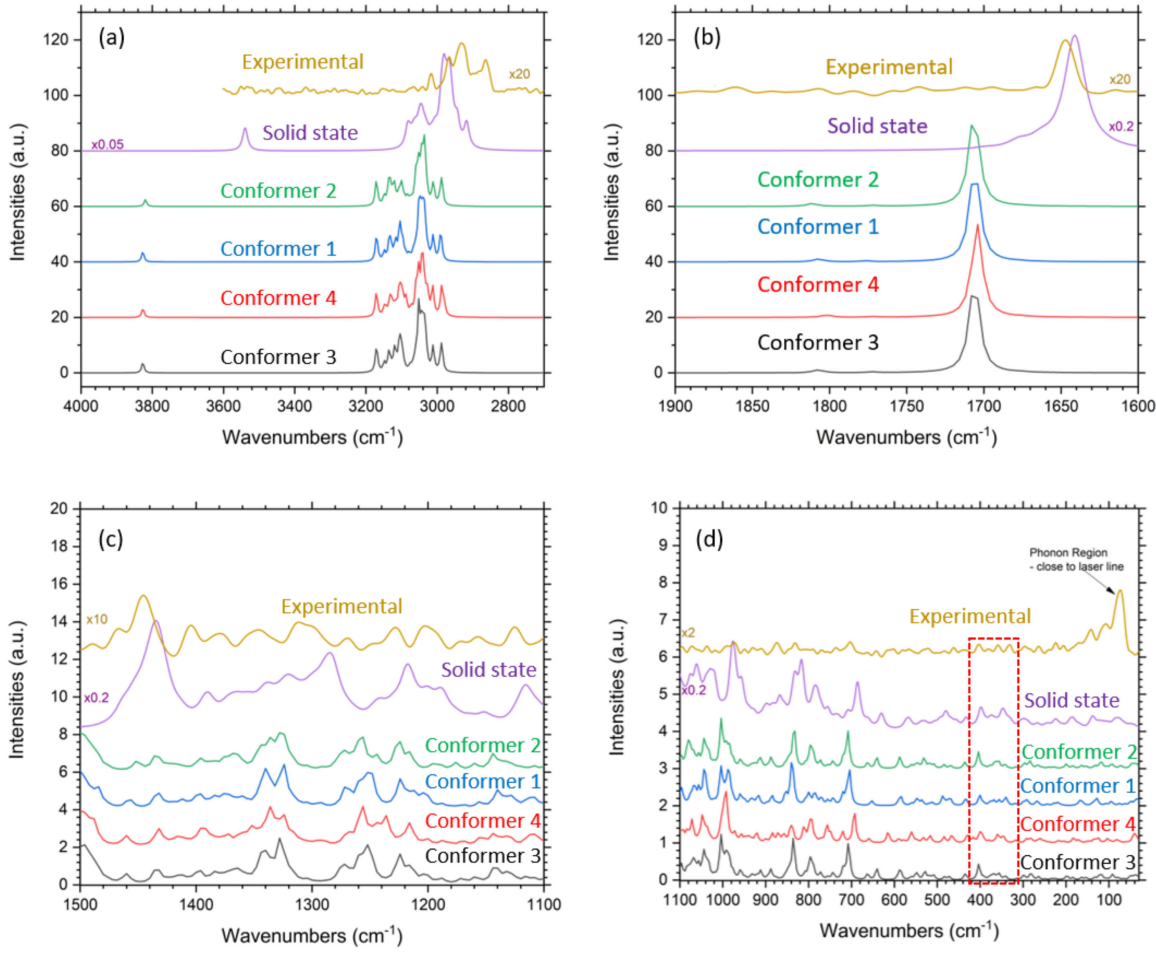

Figure 5. Comparison of the Raman spectra of lovastatin powder (yellow) to the calculated spectrum of the solid (purple) and the gas-phase spectra of the four low-energy conformers identified from the gas-phase potential energy surface (PES) scans in Figure 1 (blue, green, black, red). The spectra are shown in four separate regions, viz. $2700-4000 \mathrm{~cm}^{-1}$ (a), $1600-1900 \mathrm{~cm}^{-1}$ (b) and $1100-1500 \mathrm{~cm}^{-1}$ (c) and $20-1100 \mathrm{~cm}^{-1}(\mathrm{~d})$. The red box in (d) highlights differences in the C-O out-of-plane deformations. All six sets of spectra have been adjusted to similar intensity scales.

As observed in the IR spectra, the calculated solid-state spectrum broadly agrees with the experimental measurements, but with the $\mathrm{C}-\mathrm{H}$ vibrations and $\mathrm{C}=\mathrm{O}$ stretches in the latter occurring at lower and higher wavenumbers, respectively. The calculated Raman spectra of the gas-phase conformers again highlight that the vibrations in the gas phase generally occur at higher frequencies than in the solid state.

As in the IR spectra, the simulated solid-state Raman spectrum shows a clear O-H peak at $3538 \mathrm{~cm}^{-1}$ which is not seen in the measured spectrum (Figure 5a). This discrepancy could be due to our choice of a $1064 \mathrm{~nm}$ laser-since the Raman intensity scales as the fourth power of the wavelength used [66], it is possible that there was insufficient photon flux to excite this particular vibration. Notably, the intensity pattern of the C-H stretches predicted from the solid-state calculations is similar to that of Conformer 1, whereas the intensity pattern in the measured spectrum resembles a mixture of Conformers 1 and 2. The bulk conformation is close to Conformer 1, albeit with a small conformational adjustment [9], whereas our MD simulations suggested that the reoriented $\mathrm{O}-\mathrm{H}$ bond in Conformer 2 is likely to be strongly disfavored in the bulk. This observation is therefore again consistent with Conformer 2 being present at the surface, as suggested by the IR spectra.

The $C=C$ stretching peaks occur at $1647 \mathrm{~cm}^{-1}$ in the experimental spectrum (Figure $5 \mathrm{~b}$ ). The gas-phase calculations predict that the $\mathrm{C}=\mathrm{O}$ stretching at $\sim 1808 \mathrm{~cm}^{-1}$ has much lower intensity than the $\mathrm{C}=\mathrm{C}$ stretching. This, together with the fact that the experimental data were collected using a $1064 \mathrm{~nm}$ laser, could suggest that the $\mathrm{C}=\mathrm{O}$ stretches were perhaps not observed experimentally. In the calculated solid-state spectra, the $\mathrm{C}=\mathrm{O}$ stretches appear as broad shoulders at 1663 and $1676 \mathrm{~cm}^{-1}$. 
Table 3. Tentative Raman peak assignments for the reference experimental spectrum $(1064 \mathrm{~nm})$ and the simulated spectra of solid-state lovastatin and the four low-energy gas-phase conformers identified from the PES scan. Abbreviations: br-broad, sh—shoulder, s—sharp, w—weak, vw—very weak.

\begin{tabular}{|c|c|c|c|c|c|c|}
\hline Solid-State & Experimental & $\begin{array}{c}\text { Tentative } \\
\text { Assignment }\end{array}$ & $\begin{array}{l}\text { Conformer } 1 \\
\text { (Gas Phase) }\end{array}$ & $\begin{array}{l}\text { Conformer } 2 \\
\text { (Gas Phase) }\end{array}$ & $\begin{array}{l}\text { Conformer } 3 \\
\text { (Gas Phase) }\end{array}$ & $\begin{array}{l}\text { Conformer } 4 \\
\text { (Gas Phase) }\end{array}$ \\
\hline $185,138,84,76$ & $173,142,110,73$ & $\begin{array}{l}\text { Lattice phonon } \\
\text { modes }\end{array}$ & \multicolumn{4}{|c|}{ Phonon bands not observed in gas-phase molecules } \\
\hline $224,268,297$ & & $\begin{array}{l}\text { (Unsaturated) } \\
\mathrm{CH}_{3} \text { torsional } \\
\text { vibration }\end{array}$ & $300,292,268$ & $296,284,268$ & $300,280,264$ & $300,280,260$ \\
\hline $\begin{array}{c}343(\mathrm{sh}), 347,374 \\
399\end{array}$ & $404,380,357$ & $\begin{array}{l}\text { C-O out-of-plane } \\
\text { deformation } \\
\text { vibration }\end{array}$ & $\begin{array}{c}376,368,356,340 \\
316(\mathrm{vw})\end{array}$ & $364,356,344$ & $368,356,340$ & $360,348,316$ \\
\hline $\begin{array}{l}570,536,527,490 \\
\text { (sh), 480, 454, } 432\end{array}$ & $\begin{array}{l}\text { Not visible above } \\
\text { FT noise }\end{array}$ & $\begin{array}{c}\text { Aliphatic } \mathrm{C}-\mathrm{CH}_{3} \\
\text { stretches/ring } \\
\text { deformation/C-O } \\
\text { in-plane } \\
\text { deformation } \\
\text { vibration }\end{array}$ & $\begin{array}{l}584,548,536,512 \\
488,472,432,400\end{array}$ & $\begin{array}{c}588,560,548,528 \\
516,508,484,472 \\
436,404\end{array}$ & $\begin{array}{c}588,560,548,528 \\
508,484,472,436 \\
404\end{array}$ & $\begin{array}{c}616,592,560,532, \\
516,484,464,428, \\
416,400\end{array}$ \\
\hline 631 & 655 & $\begin{array}{l}\text { O-H out-of-plane } \\
\text { deformation }\end{array}$ & 652 & 640 & 640 & 656 \\
\hline $\begin{array}{c}785,757,735,710 \\
687,664\end{array}$ & 703 & $\begin{array}{l}\text { C-H out-of-plane } \\
\text { deformation in } \\
\text { conjugated } \\
\text { vinylenes }\end{array}$ & $\begin{array}{c}788,772,756,744 \\
720,704,652\end{array}$ & $\begin{array}{c}796,772,756(\mathrm{w}) \\
740,720(\mathrm{sh}), 708 \\
664\end{array}$ & $\begin{array}{c}796,772,756,744 \\
720,708,664\end{array}$ & $\begin{array}{c}796,756,748,720, \\
692\end{array}$ \\
\hline $868,829,818$ & 873,831 & $\begin{array}{c}\text { Aliphatic } \mathrm{C}-\mathrm{CH}_{3} \\
\text { stretches }\end{array}$ & $\begin{array}{c}852,840,804(\mathrm{sh}) \\
800\end{array}$ & $\begin{array}{l}844 \text { (sh), } 836(\mathrm{sh}) \\
832,808 \text { (sh) }\end{array}$ & 848 (sh), 836, 808 & $860,856,840,812$ \\
\hline $926,900,884$ & $\begin{array}{l}\text { Not visible above } \\
\text { FT noise }\end{array}$ & $\begin{array}{l}\text { Out-of-plane C-H } \\
\text { deformation in cis } \\
\text { vinylenes }\end{array}$ & $\begin{array}{l}988,984(\mathrm{sh}), 960 \\
948,932,916,884\end{array}$ & $\begin{array}{c}984,976,960,948 \\
(w), 932(w), 928 \\
(w), 912,896,888\end{array}$ & $\begin{array}{c}976(\mathrm{sh}), 960,932 \\
(\mathrm{w}), 912(\mathrm{w}), 888 \\
(\mathrm{w})\end{array}$ & $\begin{array}{c}972,956,940,920 \\
900,884,872\end{array}$ \\
\hline $\begin{array}{c}\text { 1076, 1062, 1037, } \\
\text { 1029, 1022, 976, } \\
957,\end{array}$ & $\begin{array}{c}\text { 990, 1014, 1028, } \\
1033 \text { (sh), 1043, } \\
1054\end{array}$ & $\begin{array}{l}\text { Aliphatic C-H } \\
\text { deformation }\end{array}$ & $\begin{array}{l}\text { 1096, } 1076(\mathrm{sh}) \\
1068,1056,1044, \\
1004\end{array}$ & $\begin{array}{c}1096,1080,1072, \\
1056,1044,1032 \\
\text { (sh), 1004, } 992\end{array}$ & $\begin{array}{c}1096,1080,1068, \\
1056,1044,1032, \\
1004,992\end{array}$ & $\begin{array}{c}1092,1084,1072 \\
1048,1032,992\end{array}$ \\
\hline 1151,1115 & $\begin{array}{l}\text { Not visible above } \\
\text { FT noise }\end{array}$ & $\begin{array}{l}\text { Coupled C-O } \\
\text { stretches }\end{array}$ & $\begin{array}{l}1188,1168,1156, \\
1140,1128,1112, \\
1108(\text { all w) }\end{array}$ & $\begin{array}{c}\text { 1188, } 1176,1160 \\
1144,1132,1108 \\
(\text { all w) }\end{array}$ & $\begin{array}{l}\text { 1188, 1172, 1160, } \\
\text { 1144, 1140, 1132, } \\
1116,1108 \text { (all w) }\end{array}$ & $\begin{array}{c}1188,1172,1160, \\
1156 \text { (sh), 1144, } \\
1132,1128,1108 \\
\text { (all w) }\end{array}$ \\
\hline $\begin{array}{c}1241,1217,1200, \\
1189\end{array}$ & $\begin{array}{l}\text { Not visible above } \\
\text { FT noise }\end{array}$ & $\begin{array}{c}\text { Asymmetric } \\
\text { C-O-C stretching }\end{array}$ & $\begin{array}{l}1260 \text { (sh), 1256, } \\
1248 \text { (sh), 1224, } \\
1220 \text { (w), 1212, } \\
1204\end{array}$ & $\begin{array}{c}1260(\mathrm{sh}), 1256, \\
1244,1228,1224, \\
1216,1204,1196 \\
(\mathrm{vw})\end{array}$ & $\begin{array}{c}1260,1252,1224, \\
1204\end{array}$ & $\begin{array}{l}1256,1244,1236 . \\
1216,1200\end{array}$ \\
\hline $\begin{array}{c}1338(\mathrm{w}), 1320(\mathrm{w}) \\
1298(\mathrm{sh}), 1285\end{array}$ & $\begin{array}{l}\text { Not visible above } \\
\text { FT noise }\end{array}$ & $\begin{array}{l}\text { In-plane O-H } \\
\text { deformation and } \\
\text { symmetric C-H } \\
\text { deformation }\end{array}$ & $\begin{array}{c}1340,1324,1304 \\
(\mathrm{w}), 1292(\mathrm{w}), \\
1276(\mathrm{sh}), 1272\end{array}$ & $\begin{array}{c}1344,1336,1328, \\
1324,1304(\mathrm{w}), \\
1276(\mathrm{sh}), 1272\end{array}$ & $\begin{array}{c}1344,1340,1326, \\
1304 \text { (w), 1276, } \\
1272\end{array}$ & $\begin{array}{c}1336,1324,1316 \\
(w), 1268\end{array}$ \\
\hline $1391,1366(\mathrm{w}, \mathrm{br})$ & 1377,1404 & $\begin{array}{c}\text { In-plane O-H } \\
\text { deformation } \\
\text { coupled with C-H } \\
\text { wagging }\end{array}$ & $1384,1376,1360$ & $\begin{array}{c}1384,1376,1368, \\
1364\end{array}$ & 1384,1364 & 1372,1352 \\
\hline $\begin{array}{c}1462(\mathrm{sh}), 1436 \\
1416(\mathrm{sh})\end{array}$ & 1446,1467 & $\begin{array}{l}\text { Asymmetric C-H } \\
\text { deformation }\end{array}$ & $\begin{array}{c}1516(\mathrm{sh}), 1500 \\
1484(\mathrm{sh}), 1456, \\
1436,1432,1412, \\
1400,1396\end{array}$ & $\begin{array}{c}1516 \text { (br, sh), } 1500 \\
\text { (br), } 1484 \text { (sh) } \\
1452,1436,1432 \\
1396\end{array}$ & $\begin{array}{l}1516,1500 \text { (br), } \\
1496,1460,1436, \\
1432,1412,1396\end{array}$ & $\begin{array}{c}1516 \text { (sh), } 1508 \\
\text { (sh), } 1500 \text { (br) } \\
1488,1460,1432, \\
1428 \text { (sh), 1416, } \\
1392\end{array}$ \\
\hline $\begin{array}{l}1641,1663(\mathrm{sh}), \\
1676(\mathrm{sh})\end{array}$ & 1647 (br) & $\begin{array}{c}\mathrm{C}=\mathrm{C} \text { symmetric } \\
\text { stretching in } \\
\text { dienes, } \mathrm{C}=\mathrm{O} \text { in } \\
\text { esters? }\end{array}$ & $\begin{array}{c}1808,1716(\mathrm{sh}), \\
1712(\mathrm{sh}), 1708, \\
1704(\mathrm{~s}), 1700(\mathrm{sh})\end{array}$ & $\begin{array}{c}1812,1716(\mathrm{sh}) \\
1712(\mathrm{sh}), 1708(\mathrm{~s}) \\
1704,1700(\mathrm{sh})\end{array}$ & $\begin{array}{l}1808,1712 \text { (sh), } \\
1708,1704,1700 \\
\text { (sh) }\end{array}$ & $\begin{array}{l}1800,1708(\mathrm{sh}), \\
1704,1700(\mathrm{sh})\end{array}$ \\
\hline $\begin{array}{l}3008(\mathrm{sh}), 2981, \\
2964,2944(\mathrm{sh}), \\
2917\end{array}$ & $\begin{array}{l}2989 \text { (sh), 2966, } \\
2950,2930,2864\end{array}$ & $\begin{array}{l}\text { Aliphatic C-H } \\
\text { stretching (both } \\
\text { symmetric and } \\
\text { asymmetric In } \\
\mathrm{CH}_{2} \text { and } \mathrm{CH}_{3} \text { ) }\end{array}$ & $\begin{array}{l}3060(\mathrm{sh}), 3048, \\
3040,3012,2988\end{array}$ & $\begin{array}{l}3060(\mathrm{sh}), 3052, \\
3044,3036,3012, \\
2988\end{array}$ & $\begin{array}{c}3052,3046,3012 \\
2988\end{array}$ & $\begin{array}{c}3060(\mathrm{sh}), 3052, \\
3040,3028(\mathrm{sh}) \\
3012,2988\end{array}$ \\
\hline $3082,3063,3045$ & 3015 (s) & $\begin{array}{l}\text { Olefinic C-H } \\
\text { stretching }\end{array}$ & $\begin{array}{l}3172,3148,3136 \\
(\mathrm{sh}), 3132,3116, \\
3104,3080(\mathrm{w})\end{array}$ & $\begin{array}{c}3172,3148(w), \\
3136,3120,3100, \\
3084(w)\end{array}$ & $\begin{array}{c}3172,3148,3136, \\
3120,3104,3076 \\
(w)\end{array}$ & $\begin{array}{c}3172,3148,3132 \\
3104,3088(\mathrm{sh})\end{array}$ \\
\hline 3538 & $\begin{array}{l}\text { Not visible above } \\
\text { FT noise }\end{array}$ & $\begin{array}{l}\text { O-H stretching } \\
\text { (with } \\
\text { intermolecular } \\
\text { H-bonding) }\end{array}$ & 3828 & 3820 & 3828 & 3828 \\
\hline
\end{tabular}


The thermal background noise in the spectra prohibits reliable identification of the thiol groups observed in the IR measurements. Features in the fingerprint region from 1100 to $500 \mathrm{~cm}^{-1}$ also had a poor signal-to-noise ratio and could only be reliably discerned after applying 7-point FFT smoothing to de-noise the spectra. The intensity patterns generally resemble the calculated solid-state spectrum (Figure $5 \mathrm{c}$ ). However, the smoothing of already low-intensity features means that the peak positions may not be reliable, so we refrain from making assignments. The intensity pattern of the C-O out-of-plane deformations between 300 and $400 \mathrm{~cm}^{-1}$ is similar to that predicted in the simulated solid-state spectrum and in the simulated gas-phase spectrum of Conformer 1.

The prominent phonon peak at $110 \mathrm{~cm}^{-1}$ in the experimental spectrum (Figure $5 \mathrm{~d}$ ) is notably absent in the solid-state calculations. There are several possible origins for this discrepancy. The first is that PBE-D3 may incorrectly predict the change in polarizability along the low-frequency modes. The second is that the calculations predict too high an intensity for the strongest bands, so that the relative intensities of the phonon bands are too weak. A third possibility is that the positional disorder in the real structure and consequent symmetry breaking could allow for phonon modes away from the Brillouin zone center to become Raman-active, resulting in an increase in the intensity that is not accounted for in our calculations on a single unit cell. The phonon region of the lovastatin vibrational spectrum has previously been investigated using terahertz spectroscopy [34] and low-wavenumber Raman [28], and these studies found a generally good match between experiment and theory. Our calculations are generally consistent with these previous studies, with calculated vibrational modes at or close to features in the measured terahertz and inelastic neutron scattering spectra in Ref. [34].

Overall, the Raman measurements do not provide a conclusive identification of the conformer(s) present at the surfaces, but do support the inference from the IR measurements that appreciable amounts of Conformer 2 may be present at the surface. Polarized Raman experiments on single crystals with a shorter-wavelength laser might be used in conjunction with modeling, as in our previous study [27], to better probe the functional group orientations at the crystal surfaces. However, since lovastatin tends to form needlelike crystals [67], growing single crystals with sufficient surface area for a typical beam spot size is likely to prove challenging.

\subsubsection{X-ray Photoelectron Spectroscopy (XPS)}

Given its high surface sensitivity, we also investigated whether XPS measurements might be useful for investigating surface conformations. As described in the Materials and Methods section, the C1s and O1s spectra of the four low-energy conformers identified from the gas-phase PES scans were calculated by treating the atomic energies obtained using the method of Natural Atomic Orbitals as binding energies. We stress once again that this is a very approximate method, and that binding energy shifts of 11.5 and $18 \mathrm{eV}$ needed to be applied to the $\mathrm{C} 1 \mathrm{~s}$ and $\mathrm{O} 1 \mathrm{~s}$ spectra, respectively, to match the experimental energy ranges. We therefore use the calculations for qualitative comparison only.

Figure 6a,b show how the simulated C1s and O1s spectra of the lowest-energy gasphase conformer, Conformer 1, are obtained by summing contributions from the individual atoms. The $11.5 \mathrm{eV}$ shift adjusts the spectra so that the aliphatic $\mathrm{C} 1$ s binding energy is centered at a reference value of $285.0 \mathrm{eV}$, similar to the calibration method that we have used in previous XPS studies of organic materials [68]. Similarly, the $18 \mathrm{eV}$ shift applied to the $\mathrm{O} 1 \mathrm{~s}$ spectra adjusts the $\mathrm{C}-\mathrm{O}$ peak to match the typical binding energy of $534.5 \mathrm{eV}$. 

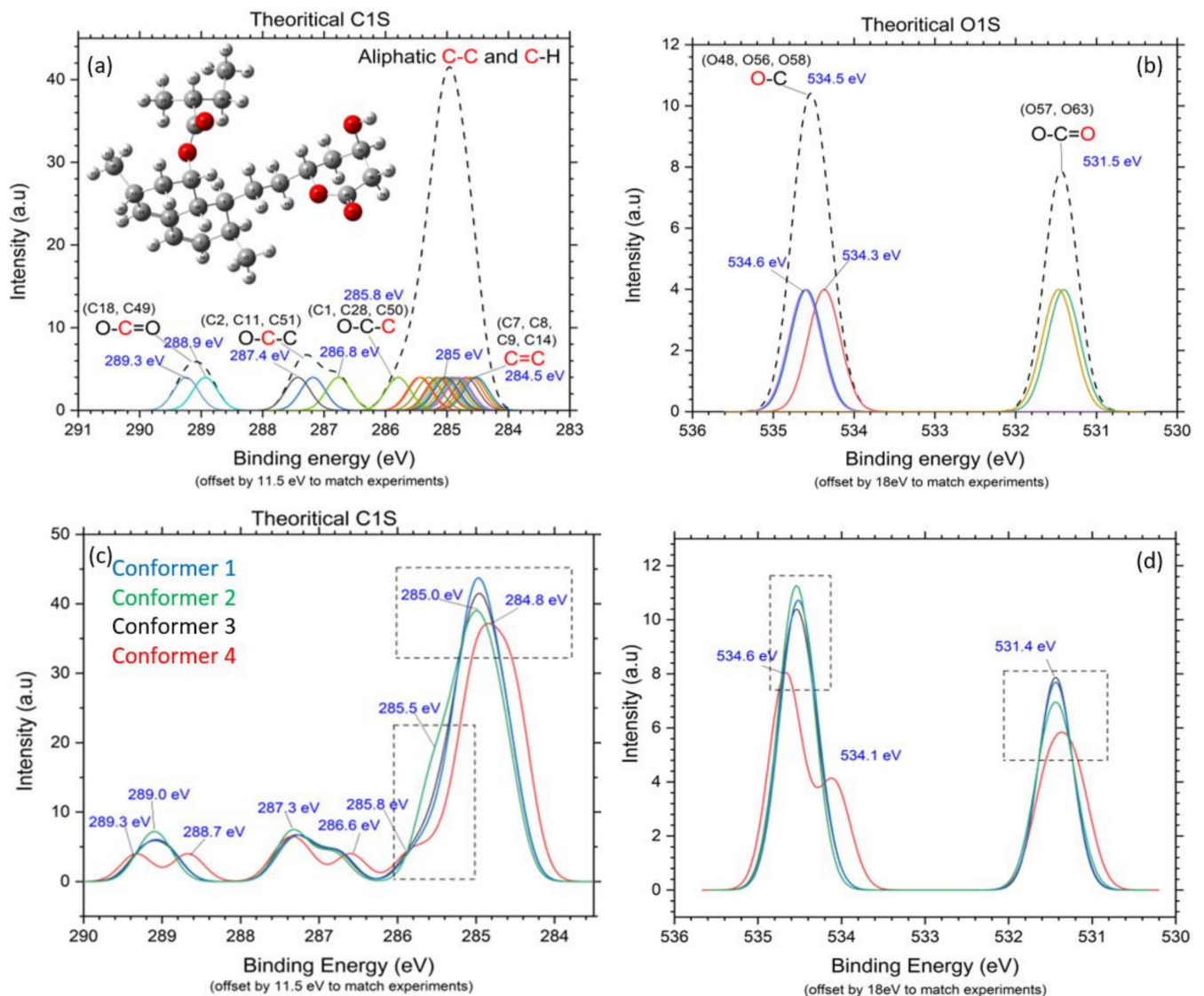

Figure 6. Simulated X-ray photoelectron spectra (XPS) of the four low-energy gas-phase conformers of lovastatin identified from the potential energy surface scans. Plots $(\mathbf{a}, \mathbf{b})$ show how contributions from individual $\mathrm{C}$ and $\mathrm{O}$ atoms are combined to form the simulated C1s and O1s spectra, respectively, for the lowest-energy conformer, Conformer 1 . The spectra are generated as a sum of Gaussian functions with unit area, centered on the NAO energies, and with a broadening of width $\sigma=0.2 \mathrm{eV}$. An image of the molecule showing the atom labels is given in Figure 1e. Plots (c,d) compare the C1s and O1s simulated spectra of the four conformers. The boxes highlight regions of the spectra where components are predicted to have binding energy differences greater than $0.1 \mathrm{eV}$, which most likely could not be resolved experimentally due to being much less than the natural linewidth.

After shifting, the $\mathrm{C} 1 \mathrm{~s}$ component from the $\mathrm{C}=\underline{\mathrm{C}}$ in Conformer 1 is predicted to occur at around $284.5 \mathrm{eV}$, and the $\mathrm{C} 1 \mathrm{~s}$ peaks arising from aliphatic carbons are predicted to span a range of $284.8-285.4 \mathrm{eV}$, centered at $285 \mathrm{eV}$ (Figure $6 \mathrm{a}$ ). The $\mathrm{C}-\mathrm{C}-\mathrm{O} \mathrm{C}$ atoms are predicted to give rise to $\mathrm{C} 1 \mathrm{~s}$ peaks at $285.8 \mathrm{eV}$, which is a $0.4 \mathrm{eV}$ higher binding energy than the other aliphatic carbons. The $\mathrm{C} 1 \mathrm{~s}$ peaks arising from the $\mathrm{C}-\mathrm{O}$ atoms are predicted to produce two distinct peaks at $286.8 \mathrm{eV}$ and $287.4 \mathrm{eV}$, while peaks arising from $\mathrm{O}-\mathrm{C}=\mathrm{O}$ are centered at $289.0 \mathrm{eV}$. In both cases where the $\mathrm{C}$ is bonded to an $\mathrm{O}$, the peaks occur at a higher binding energy for atoms in the pyranyl ring compared to those in the $S$-butanoate group. The simulated $\mathrm{O} 1 \mathrm{~s}$ spectrum of Conformer 1 (Figure $6 \mathrm{~b}$ ) shows features from the $\mathrm{O}-\mathrm{C}=\underline{\mathrm{O}}$ atoms centered at $531.5 \mathrm{eV}$, while those due to C-O atoms are centered at $534.5 \mathrm{eV}$.

The simulated C1s and O1s spectra (Figure 6c,d) of Conformers 1 and 3 are extremely similar, while the $\mathrm{C} 1 \mathrm{~s}$ features from the $\mathrm{C}-\mathrm{C}-\mathrm{O}$ atoms in Conformer 2 are predicted to shift to a $0.3 \mathrm{eV}$ lower binding energy. However, the resulting changes to the overall $\mathrm{C} 1 \mathrm{~s}$ spectrum, indicated by the black boxes in Figure $6 c, d$, are of the order of $0.1-0.3 \mathrm{eV}$ and may not be detectable. On the other hand, Conformer 4 shows a clear shift in the $\mathrm{C} 1 \mathrm{~s}$ and $\mathrm{O} 1 \mathrm{~s}$ features arising from the $\mathrm{C}-\mathrm{O}$ and $\mathrm{O}-\mathrm{C}=\underline{\mathrm{O}}$ atoms of the $\mathrm{S}$-butanoate group, which can be related to the increased vdW interactions identified in the analysis in Figure 3, together with a subtle increase in the $\mathrm{C}-\mathrm{O}$ bond length (c.f. Table 1). These shifts are of the order 
of $0.5 \mathrm{eV}$ or greater and hence likely could be detected experimentally if an appreciable population of Conformer 4 were to be present.

The survey NAP XP spectrum of lovastatin (Figure 7a) indicates an elemental composition of $74.6 \% \mathrm{C}$ and $11.5 \% \mathrm{O}$ with $6.6 \% \mathrm{~N}$ and $7.3 \% \mathrm{Ar}$ from residual air and charge compensation gas, respectively. Based on the lovastatin stoichiometry, the elemental composition is expected to be $83 \% \mathrm{C}$ and $17 \% \mathrm{O}$. Assuming that the entire $\mathrm{O}$ signal in the survey spectrum can be attributed to lovastatin, there would be $\sim 25$ at. \% excess $\mathrm{C}$ present. A common source of such excess $C$ is adventitious carbon contamination from the environment, which is commonly found [68] on materials that have been exposed to air. There may also be impurities in the as-received material, such as $\mathrm{N}$ in malonyl CoA, as noted previously.
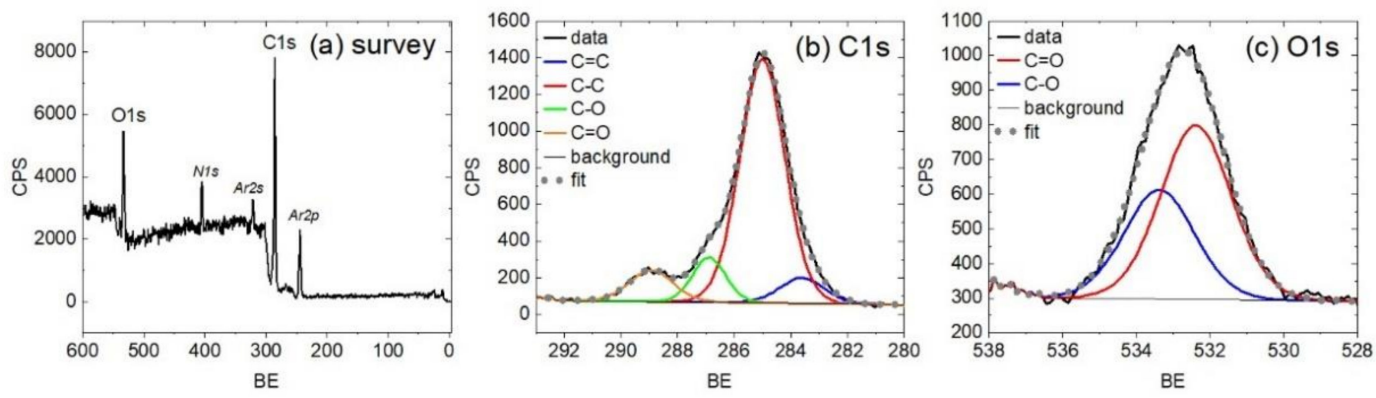

Figure 7. Near ambient pressure X-ray photoelectron spectra (XPS) of lovastatin powder: (a) survey scan; (b) high-resolution $\mathrm{C} 1 \mathrm{~s}$ region; and (c) high-resolution O1s region.

The C1s core-level spectrum of lovastatin was analyzed by peak fitting using four components, without constraints, reflecting the expected contributions of the four primary $\mathrm{C}$ moieties in the molecule to the total peak area. These are as follows: $4 \mathrm{sp}^{2} \mathrm{C}$ atoms in the in the two $\mathrm{C}=\mathrm{C}$ bonds $(17 \%), 15 \mathrm{sp}^{3}$ aliphatic carbon atoms $(62 \%), 3 \mathrm{C}(12 \%)$ in a single bond to a heteroatom (alcohol and ester) and $2 \mathrm{C}$ atoms in the $\mathrm{C}=\mathrm{O}$ carbonyl groups $(8 \%)$. The components have similar FWHM $(\sim 1.8 \mathrm{eV})$ except for the component reflecting $\mathrm{C}$ atoms in the ester and alcohol functional groups, which has a slightly narrower FWHM $(1.3 \mathrm{eV})$. The narrower FWHM suggests that these $\mathrm{C}$ atoms are in more similar chemical environments than the $\mathrm{C}$ atoms contributing to other components of the spectrum. The fit approximates the relative theoretical contributions of the four clusters of functional groups plus those from adventitious carbon to the spectral envelope. The fit also broadly agrees with the trends in the calculated C 1s spectra of the gas-phase lovastatin conformers (c.f. Figure 6c).

The O1s core-level spectrum was fitted with 2 peaks, with an equal FWHM broader than those of the $\mathrm{C} 1 \mathrm{~s}$ components, reflecting $3 \mathrm{O}$ atoms at lower $\mathrm{BE}$ contributing $60 \%$ to the total intensity and $2 \mathrm{O}$ atoms at higher BE contributing to the remaining $40 \%$ of the overall intensity. Based on the molecular structure of lovastatin, one expects the contributions to be reversed, with the $2 \mathrm{O}$ atoms from the carbonyl group contributing to the spectral envelope at a lower binding energy than the $3 \mathrm{O}$ atoms in the ester and alcohol species. This result would also be in line with the relative contributions of these species observed in the calculated O1s spectra. However, neither of these interpretations account for the impact of non-covalent inter- or intramolecular interactions on the electron density of $\mathrm{O}$ atoms of lovastatin in the solid state. For example, computational studies of crystalline lovastatin [2] have identified that non-covalent intermolecular interactions involving the $\mathrm{O}$ atoms in the carbonyl and alcohol functional groups make significant contributions to stabilizing the crystal lattice. These include a short intermolecular contact between the carbonyl and an acidic proton on adjacent pyranyl rings and a long H-bond between a carbonyl group on the butanoate ester and an alcohol on an adjacent pyranyl ring. Redistribution of electron density at the $\mathrm{O}$ atoms from these electrostatic interactions is well known to shift the binding energies of the core-level electrons [69] by a similar magnitude to the shifts observed in the O1s spectrum presented here. The relatively broader peaks in the O1s 
spectrum also suggest that the $5 \mathrm{O}$ species might be distributed over more than just two defined states. Resolving these details is, however, impossible without a better systematic understanding of core-level binding energy shifts as a function of the exact proton positions within the hydrogen bonds. The influence of these non-covalent interactions on the corelevel binding energies is stronger than the effects of conformational change (Figure 6), and a deeper understanding of the dynamic and static disorder of protons, as well as the depths of the PES of H-bonding, will be needed to identify the preferred conformation of lovastatin in the solid state.

\section{Discussion}

Gas-phase conformational analyses of the main bond torsions identify four low-energy conformers that would be expected to show appreciable populations at room temperature. Analysis of the electrostatic potentials and non-covalent interactions does not suggest any particular electrostatic interactions that would make one conformer lower in energy than the other, so the energy differences likely arise from a subtle balance of intramolecular interactions. The relative energies suggest a $21.8 \%$ occupation of a second conformer at $290 \mathrm{~K}$, with the O-H group on the pyranyl ring pointing $180^{\circ}$ to that in the other conformers. Across the four low-energy gas-phase conformers, the two main chains of the molecule comprising the $S$-butanoate and the lactone do not exhibit changes to any torsion that are greater than $120^{\circ}$, thereby concurring with previous studies [9] about the absence of conformational polymorphism. Solid-state molecular dynamics simulations, on the other hand, suggest that the $\mathrm{O}-\mathrm{H}$ group is locked in position in bulk by a strong $\mathrm{H}$-bonding interaction with the neighboring $\mathrm{C}=\mathrm{O}$ group. The disorder observed in the crystal structure is instead due to the butyl group on the S-butanoate moiety, and the MD simulations suggest co-operative movement molecules in adjacent unit cells along the short $a$ direction.

A comparison of measured vibrational spectra to simulated spectra of bulk lovastatin and the gas-phase conformations suggests that an appreciable amount of the second conformer may be found at crystal surfaces, where the group is able to rotate freely. In particular, the olefinic $\mathrm{C}-\mathrm{H}$ stretching vibrations from the hexahydronaphathenyl group, the coupled in-plane O-H deformation and symmetric C-H deformation and the appearance of the out-of-place O-H deformation at $656 \mathrm{~cm}^{-1}$ in the experimental IR spectrum support the presence of the second conformer at the surface. The intensity pattern of the $\mathrm{C}-\mathrm{H}$ region in the FT-Raman spectrum also suggests a combination of the two lowest-energy gas-phase conformers, again supporting the presence of the second conformer at the surface. The implication of this is that lovastatin crystal surfaces likely expose free $\mathrm{O}-\mathrm{H}$ groups and are therefore not chemically inert.

While experimental and computed XPS generally agree, we found little observable difference between the two prominent low-energy gas-phase conformers. Better distinction between conformers and impurities present on the true surface and sub-surface will require more detailed studies using variable photon energy and angle-dependent XPS experiments [70].

We also observed evidence in our measurements for the presence of malonyl CoA impurities in our commercial lovastatin sample. XPS measurements indicate a small at. \% of $\mathrm{N}$, which is difficult to identify in IR spectra due to the relatively weak $\mathrm{N}-\mathrm{H}$ vibrations, while S-H vibrations are evident in the IR spectra but are not observed in XPS due to the lower sensitivity to $S$. These two measurements are therefore complementary.

Overall, the combination of gas-phase and solid-state modeling and spectroscopy has provided valuable insight into the conformational flexibility of the lovastatin molecule in bulk and at the particle surfaces, in a powder sample. In the future, our protocol could be improved on by performing polarized Raman measurements, as well as angle-resolved XPS measurements on clean single-crystal surfaces. This combined approach could be applied to a wide range of molecular solids, and we therefore hope that our work will serve as a first step towards a robust protocol for the routine analysis of particle surfaces. 
Supplementary Materials: The following are available online at https: / www.mdpi.com/article/ 10.3390/cryst11050509/s1: Molecular dynamics data, electrostatic potential data, character table of point group D2 (222), chemical environment in lovastatin molecule with atom labels, and calculated XPS peaks as a function of various dihedral angles.

Author Contributions: Conceptualization, A.R.P.; methodology, A.R.P., J.M.S., S.L.M.S.; formal analysis, A.R.P., E.A.W. and J.M.S.; investigation, A.R.P., E.A.W., A.B.; resources, S.L.M.S., E.A.W. and J.M.S.; data curation, A.R.P.; writing—original draft preparation, A.R.P.; writing-review and editing, A.R.P., J.M.S., E.A.W., A.B. and S.L.M.S.; funding acquisition, S.L.M.S. and J.M.S. All authors have read and agreed to the published version of the manuscript.

Funding: The authors acknowledge the Research Complex at Harwell ( $\mathrm{RCaH})$ facility for the use of laboratory facilities, with financial support from the Future Continuous Manufacturing and Advanced Crystallization (CMAC) Hub (UK Engineering and Physical Sciences Research Council grant EP/P006965/1). Parts of the calculations in this work were performed on the UK Archer highperformance computing facility through membership of the UK Materials Chemistry Consortium (MCC), which is funded by the EPSRC (EP/L000202, EP/R029431). JMS is supported by a UK Research and Innovation Future Leaders Fellowship (MR/T043121/1).

Institutional Review Board Statement: Not applicable.

Informed Consent Statement: Not applicable.

Data Availability Statement: Not applicable.

Acknowledgments: J.M.S. is grateful to UK Research and Innovation for the support of a Future Leaders Fellowship, and to Manchester University for the support of a Presidential Fellowship. Some of the calculations in this work were performed on the University of Manchester Computational Shared Facility (CSF), which is maintained by UoM Research IT. S.L.M.S. is supported by the Royal Academy of Engineering, Diamond Light Source Ltd. and Infineum UK as the Bragg Centenary Chair.

Conflicts of Interest: The authors declare no conflicts of interest.

\section{References}

1. Hatcher, L.E.; Li, W.; Payne, P.; Benyahia, B.; Rielly, C.D.; Wilson, C.C. Tuning morphology in active pharmaceutical ingredients: Controlling the crystal habit of lovastatin through solvent choice and non-size-matched polymer additives. Cryst. Growth Des. 2020, 20, 5854-5862. [CrossRef]

2. Turner, T.D.; Hatcher, L.E.; Wilson, C.C.; Roberts, K.J. Habit Modification of the Active Pharmaceutical Ingredient Lovastatin Through a Predictive Solvent Selection Approach. J. Pharm. Sci. 2019, 108, 1779-1787. [CrossRef]

3. Dove, J.W.; Buckton, G.; Doherty, C. A comparison of two contact angle measurement methods and inverse gas chromatography to assess the surface energies of theophylline and caffeine. Int. J. Pharm. 1996, 138, 199-206. [CrossRef]

4. Buckton, G.; Newton, J.M. Assessment of the wettability and surface energy of a pharmaceutical powder by liquid penetration. J. Pharm. Pharmacol. 1985, 37, 605-609. [CrossRef]

5. Duncan-Hewitt, W.; Nisman, R. Investigation of the Surface Free Energy of Pharmaceutical Materials from Contact Angle, Sedimentation, and Adhesion Measurements. J. Adhes. Sci. Technol. 1993, 7, 263-283. [CrossRef]

6. Modi, S.R.; Dantuluri, A.K.R.; Perumalla, S.R.; Sun, C.C.; Bansal, A.K. Effect of crystal habit on intrinsic dissolution behavior of celecoxib due to differential wettability. Cryst. Growth Des. 2014, 14, 5283-5292. [CrossRef]

7. Sarisuta, N.; Lawanprasert, P.; Puttipipatkhachorn, S. The Influence of Drug-Excipient and Drug-Polymer Interactions on Butt Adhesive Strength of Ranitidine Hydrochloride Film-Coated Tablets. Drug Dev. Ind. Pharm. 2006, 32, 463-471. [CrossRef] [PubMed]

8. Williams, D. Particle Engineering in Pharmaceutical Solids Processing: Surface Energy Considerations. Curr. Pharm. Des. 2015, 21, 2677-2694. [CrossRef] [PubMed]

9. Cruz-Cabeza, A.J.; Bernstein, J. Conformational polymorphism. Chem. Rev. 2014, 114, 2170-2191. [CrossRef]

10. Nangia, A. Conformational polymorphism in organic crystals. Acc. Chem. Res. 2008, 41, 595-604. [CrossRef]

11. Krimm, S. Interpreting infrared spectra of peptides and proteins. ACS Symp. Ser. 2000, 750, 38-53. [CrossRef]

12. Fink, A.L.; Seshadri, S.; Khurana, R.; Oberg, K.A. Determination of secondary structure in protein aggregates using attenuated total reflectance FTIR. ACS Symp. Ser. 2000, 750, 132-144. [CrossRef]

13. Baiz, C.R.; Błasiak, B.; Bredenbeck, J.; Cho, M.; Choi, J.-H.; Corcelli, S.A.; Dijkstra, A.G.; Feng, C.-J.; Garrett-Roe, S.; Ge, N.-H.; et al. Vibrational Spectroscopic Map, Vibrational Spectroscopy, and Intermolecular Interaction. Chem. Rev. 2020. [CrossRef] [PubMed]

14. Ouvrard, C.; Price, S.L. Toward crystal structure prediction for conformationally flexible molecules: The headaches illustrated by aspirin. Cryst. Growth Des. 2004, 4, 1119-1127. [CrossRef] 
15. Du, W.; Wang, H.; Wang, R.; Wang, X.; Cheng, P.; Zhang, J.; Tang, N.; Zhu, L.; Cui, P. Conformational Flexibility and Crystallization: The Case of 4-Hexyloxybenzoic Acid. Cryst. Growth Des. 2020. [CrossRef]

16. Mary, Y.S.; Raju, K.; Panicker, C.Y.; Al-Saadi, A.A.; Thiemann, T. Molecular conformational analysis, vibrational spectra, NBO analysis and first hyperpolarizability of (2E)-3-(3-chlorophenyl)prop-2-enoic anhydride based on density functional theory calculations. Spectrochim. Acta Part A Mol. Biomol. Spectrosc. 2014, 131, 471-483. [CrossRef]

17. Sebastian, S.; Sylvestre, S.; Jayabharathi, J.; Ayyapan, S.; Amalanathan, M.; Oudayakumar, K.; Herman, I.A. Study on conformational stability, molecular structure, vibrational spectra, NBO, TD-DFT, HOMO and LUMO analysis of 3,5-dinitrosalicylic acid by DFT techniques. Spectrochim. Acta Part A Mol. Biomol. Spectrosc. 2015, 136, 1107-1118. [CrossRef]

18. Sheena Mary, Y.; Raju, K.; Panicker, C.Y.; Al-Saadi, A.A.; Thiemann, T.; Van Alsenoy, C. Molecular conformational analysis, vibrational spectra, NBO analysis and first hyperpolarizability of (2E)-3-phenylprop-2-enoic anhydride based on density functional theory calculations. Spectrochim. Acta Part A Mol. Biomol. Spectrosc. 2014, 128, 638-646. [CrossRef]

19. Singh, H.; Singh, S.; Srivastava, A.; Tandon, P.; Bharti, P.; Kumar, S.; Maurya, R. Conformational analysis and vibrational study of daidzein by using FT-IR and FT-Raman spectroscopies and DFT calculations. Spectrochim. Acta Part A Mol. Biomol. Spectrosc. 2014, 120, 405-415. [CrossRef] [PubMed]

20. Kalaichelvan, S.; Sundaraganesan, N.; Dereli, O.; Sayin, U. Experimental, theoretical calculations of the vibrational spectra and conformational analysis of 2,4-di-tert-butylphenol. Spectrochim. Acta Part A Mol. Biomol. Spectrosc. 2012, 85, 198-209. [CrossRef]

21. Mavromoustakos, T.; Kolocouris, A.; Zervou, M.; Roumelioti, P.; Matsoukas, J.; Weisemann, R. An effort to understand the molecular basis of hypertension through the study of conformational analysis of Losartan and Sarmesin using a combination of nuclear magnetic resonance spectroscopy and theoretical calculations. J. Med. Chem. 1999, 42, 1714-1722. [CrossRef]

22. Gil, R.R. Constitutional, configurational, and conformational analysis of small organic molecules on the basis of NMR residual dipolar couplings. Angew. Chemie Int. Ed. 2011, 50, 7222-7224. [CrossRef] [PubMed]

23. Brooks, C.L.; Case, D.A. Simulations of Peptide Conformational Dynamics and Thermodynamics. Chem. Rev. 1993, 93, 2487-2502. [CrossRef]

24. Casalegno, M.; Moret, M.; Resel, R.; Raos, G. Surface Reconstructions in Organic Crystals: Simulations of the Effect of Temperature and Defectivity on Bulk and (001) Surfaces of 2,2':6', $2^{\prime \prime}$-Ternaphthalene. Cryst. Growth Des. 2016, 16, 412-422. [CrossRef] [PubMed]

25. Nemkevich, A.; Bürgi, H.B.; Spackman, M.A.; Corry, B. Molecular dynamics simulations of structure and dynamics of organic molecular crystals. Phys. Chem. Chem. Phys. 2010, 12, 14916-14929. [CrossRef]

26. Tan, N.Y.; Zeitler, J.A. Probing phase transitions in simvastatin with terahertz time-domain spectroscopy. Mol. Pharm. 2015, 12, 810-815. [CrossRef]

27. Pallipurath, A.R.; Skelton, J.M.; Erxleben, A.; McArdle, P. Shining Light on Growth-Dependent Surface Chemistry of Organic Crystals: A Polarized Raman Spectroscopic and Computational Study of Aspirin. Cryst. Growth Des. 2019, 19, 1288-1298. [CrossRef]

28. Pallipurath, A.R.; Civati, F.; Sibik, J.; Crowley, C.; Zeitler, J.A.; McArdle, P.; Erxleben, A. A comprehensive spectroscopic study of the polymorphs of diflunisal and their phase transformations. Int. J. Pharm. 2017, 528, 312-321. [CrossRef]

29. Matsuoka, M. Control of crystallization. VDI Ber. 2005, 983-990. [CrossRef]

30. Jackson, K.; Young, D.; Pant, S. Drug-excipient interactions and their affect on absorption. Pharm. Sci. Technol. Today 2000, 3, 336-345. [CrossRef]

31. Beamson, G.; Pickup, B.T.; Li, W.; Mai, S.M. XPS Studies of chain conformation in PEG, PTrMO, and PTMG linear polyethers. J. Phys. Chem. B 2000, 104, 2656-2672. [CrossRef]

32. Stevens, J.S.; Byard, S.J.; Schroeder, S.L.M. Salt or Co-Crystal? Determination of Protonation State by X-Ray Photoelectron Spectroscopy (XPS). J. Pharm. Sci. 2010, 99, 4453-4457. [CrossRef] [PubMed]

33. Atzmony, L.; Lim, Y.H.; Hamilton, C.; Leventhal, J.S.; Wagner, A.; Paller, A.S.; Choate, K.A. Topical cholesterol/lovastatin for the treatment of porokeratosis: A pathogenesis-directed therapy. J. Am. Acad. Dermatol. 2020, 82, 123-131. [CrossRef] [PubMed]

34. Bilski, P.; Drużbicki, K.; Jenczyk, J.; Mielcarek, J.; Wąsicki, J. Molecular and Vibrational Dynamics in the Cholesterol-Lowering Agent Lovastatin: Solid-State NMR, Inelastic Neutron Scattering, and Periodic DFT Study. J. Phys. Chem. B 2017, 121, 2776-2787. [CrossRef]

35. Yoshida, M.I.; Oliveira, M.A.; Gomes, E.C.L.; Mussel, W.N.; Castro, W.V.; Soares, C.D.V. Thermal characterization of lovastatin in pharmaceutical formulations. J. Therm. Anal. Calorim. 2011, 106, 657-664. [CrossRef]

36. Nghiem, D.T.; Nguyen, T.C.; Do, M.T.; Nguyen, T.H.; Tran, D.L.; Hoang, T.D.; Le, V.Q.; Vu, Q.T.; Nguyen, D.T.; Thai, H. Influence of the preparation method on some characteristics of alginate/chitosan/lovastatin composites. Adv. Polym. Technol. 2020, 2020. [CrossRef]

37. Mulder, K.C.L.; Mulinari, F.; Franco, O.L.; Soares, M.S.F.; Magalhães, B.S.; Parachin, N.S. Lovastatin production: From molecular basis to industrial process optimization. Biotechnol. Adv. 2015, 33, 648-665. [CrossRef]

38. McGinty, J.; Chong, M.W.S.; Manson, A.; Brown, C.J.; Nordon, A.; Sefcik, J. Effect of process conditions on particle size and shape in continuous antisolvent crystallisation of lovastatin. Crystals 2020, 10, 925. [CrossRef]

39. Alberts, A.W.; Chen, J.; Kuron, G.; Hunt, V.; Huff, J.; Hoffman, C.; Rothrock, J.; Lopez, M.; Joshua, H.; Harris, E.; et al. Mevinolin: A highly potent competitive inhibitor of hydroxymethylglutaryl-coenzyme A reductase and a cholesterol-lowering agent. Proc. Natl. Acad. Sci. USA 1980, 77, 3957-3961. [CrossRef] 
40. Sato, S.; Hata, T.; Tsujita, Y.; Terahara, A.; Tamura, C. The structure of monacolin K, C24H26O5. Acta Crystallogr. Sect. C Cryst. Struct. Commun. 1984, 40, 195-198. [CrossRef]

41. CasaXPS. Processing Software for XPS Spectra; CasaXPS: Teignmouth, UK, 2009.

42. Frisch, M.J.; Trucks, G.W.; Schlegel, H.B.; Scuseria, G.E.; Robb, M.A.; Cheeseman, J.R.; Montgomery, J.; Vreven, T.; Kudin, K.N.; Burant, J.C.; et al. Gaussian 09 (Revision D.2); Gaussian, Inc.: Pittsburgh, PA, USA, 2009.

43. Grimme, S. Semiempirical GGA-type density functional constructed with a long-range dispersion correction. J. Comput. Chem. 2006, 27, 1787-1799. [CrossRef] [PubMed]

44. Ditchfield, R.; Hehre, W.J.; Pople, J.A. Self-consistent molecular-orbital methods. IX. An extended gaussian-type basis for molecular-orbital studies of organic molecules. J. Chem. Phys. 1971, 54, 720-723. [CrossRef]

45. Mazzanti, A.; Casarini, D. Recent trends in conformational analysis. Wiley Interdiscip. Rev. Comput. Mol. Sci. 2012, 2, 613-641. [CrossRef]

46. Tardio, S.; Cumpson, P.J. Practical estimation of XPS binding energies using widely available quantum chemistry software. Surf. Interface Anal. 2018, 5-12. [CrossRef]

47. Izumi, K.M. VESTA 3 for three-dimensional visualization of crystal, volumetric and morphology data. J. Appl. Crystallogr. 2011, $44,1272-1276$.

48. Contreras-García, J.; Johnson, E.R.; Keinan, S.; Chaudret, R.; Piquemal, J.P.; Beratan, D.N.; Yang, W. NCIPLOT: A program for plotting noncovalent interaction regions. J. Chem. Theory Comput. 2011, 7, 625-632. [CrossRef]

49. Humphrey, W.; Dalke, A.; Schulten, K. VMD: Visual molecular dynamics. J. Mol. Graph. 1996, 14, 33-38. [CrossRef]

50. Kresse, G.; Hafner, J. Abinitio molecular-dynamics for liquid-metals. Phys. Rev. B 1993, 47, 558-561. [CrossRef]

51. Perdew, J.P.; Burken, K.; Ernzerhof, M. Generalized gradient approximation made simple. Phys. Rev. Lett. 1996, 77, 3865-3868. [CrossRef]

52. Grimme, S.; Antony, J.; Ehrlich, S.; Krieg, H. A consistent and accurate ab initio parametrization of density functional dispersion correction (DFT-D) for the 94 elements H-Pu. J. Comput. Phys. 2010, 132, 154104. [CrossRef]

53. Monkhorst, H.J.; Pack, J.D. Special points for brillouin-zone integrations. Phys. Rev. B 1976, 13, 5188-5192. [CrossRef]

54. Blöchl, P.E. Projector augmented-wave method. Phys. Rev. B 1994, 50, 17953. [CrossRef] [PubMed]

55. Kresse, G.; Joubert, D. From ultrasoft pseudopotentials to the projector augmented-wave method. Phys. Rev. B 1999, 59, 1758. [CrossRef]

56. Nosé, S. A unified formulation of the constant temperature molecular dynamics methods. J. Chem. Phys. 1984, 81, 511. [CrossRef]

57. Parlinski, K.; Li, Z.Q.; Kawazoe, Y. First-principles determination of the soft mode in cubic $\mathrm{ZrO}_{2}$. Phys. Rev. Lett. 1997, 78, 4063-4066. [CrossRef]

58. Togo, A.; Tanaka, I. First principles phonon calculations in materials science. Scr. Mater. 2015, 108, 1-5. [CrossRef]

59. Skelton, J.M.; Burton, L.A.; Jackson, A.J.; Oba, F.; Parker, S.C.; Walsh, A. Lattice dynamics of the tin sulphides SnS2, SnS and Sn2S3: Vibrational spectra and thermal transport. Phys. Chem. Chem. Phys. 2017, 12452-12456. [CrossRef] [PubMed]

60. Gajdoš Hummer, K.; Kresse, G.; Furthmüller, J.; Bechstedt, F.M. Linear optical properties in the projector-augmented wave methodology. Phys. Rev. B 2006, 73, 45112. [CrossRef]

61. Gunn, D.S.D.; Skelton, J.M.; Burton, L.A.; Metz, S.; Parker, S.C. Thermodynamics, Electronic Structure, and Vibrational Properties of Snn(S1-xSex)m Solid Solutions for Energy Applications. Chem. Mater. 2019, 31, 3672-3685. [CrossRef]

62. Huang, H.; Yang, L.; Facchetti, A.; Marks, T.J. Organic and Polymeric Semiconductors Enhanced by Noncovalent Conformational Locks. Chem. Rev. 2017, 117, 10291-10318. [CrossRef]

63. Altmann, L.S.; Herzig, P. Point-Group Theory Tables; Clarendon Press: Oxford, UK, 1994; Volume xii, ISBN 0198552262.

64. Socrates, G. Infrared and Raman Characteristic Group Frequencies; John Wiley \& Sons: Hoboken, NJ, USA, 2004; ISBN 978-0-47009307-8.

65. Belwal, C.; Patel, D.; Chauhan, K.; Parmar, Y.; Rawat, A.S.; Vardhan, A. Isolation, identification and characterization of unknown impurity in fermentation based active pharmaceutical ingredient Lovastatin. Res. Rev. J. Pharm. Anal. 2014, 3, 32-41.

66. Albrecht, A.C.; Hutley, M.C. On the dependence of vibrational roman intensity on the wavelength of incident light. J. Chem. Phys. 1971, 55, 4438-4443. [CrossRef]

67. Li, J.; Tilbury, C.J.; Kim, S.H.; Doherty, M.F. A design aid for crystal growth engineering. Prog. Mater. Sci. 2016, 82, 1-38. [CrossRef]

68. Stevens, J.S.; Schroeder, S.L.M. Quantitative analysis of saccharides by X-ray photoelectron spectroscopy. Surf. Interface Anal. 2009, 41, 453-462. [CrossRef]

69. Stevens, J.S.; Coultas, S.; Jaye, C.; Fischer, D.A.; Schroeder, S.L.M. Core level spectroscopies locate hydrogen in the proton transfer pathway-identifying quasi-symmetrical hydrogen bonds in the solid state. Phys. Chem. Chem. Phys. 2020, 22, 4916-4923. [CrossRef]

70. Nakayama, Y.; Takahagi, T.; Soeda, F.; Ishitani, A.; Shimomura, M.; Kunitake, T. XPS study of oriented organic molecules. Vesicles of azobenzene-containing alkyl ammonium amphiphiles. J. Colloid Interface Sci. 1988, 122, 464-474. [CrossRef] 